\title{
Three novel species and a new record of Daldinia (Hypoxylaceae) from Thailand
}

\author{
Sarunyou Wongkanoun ${ }^{1,2} \cdot$ Kevin Becker $^{4} \cdot$ Kanthawut Boonmee $^{1} \cdot$ Prasert Srikitikulchai $^{2} \cdot$ Nattawut Boonyuen $^{3}$. \\ Boonchuai Chainuwong ${ }^{2} \cdot$ Jennifer Luangsa-ard ${ }^{3} \cdot$ Marc Stadler $^{4}$ (I)
}

Received: 17 April 2020 / Revised: 24 August 2020 / Accepted: 26 August 2020

(C) The Author(s) 2020

\begin{abstract}
In an investigation of stromatic Xylariales in Thailand, several specimens of Daldinia were discovered. Three novel species (D. flavogranulata, D. phadaengensis, and D. chiangdaoensis) were recognized from a molecular phylogeny based on concatenated ITS, LSU, RPB2, and TUB2 sequence data, combined with morphological characters and secondary metabolite profiles based on high performance liquid chromatography coupled to diode array detection and mass spectrometry (HPLC-MS). The major components detected were cytochalasins (in D. flavogranulata and D. chiangdaoensis) and daldinin type azaphilones (in D. phadaengensis). In addition, D. brachysperma, which had hitherto only been reported from America, was found for the first time in Asia. Its phylogenetic affinities were studied, confirming previous suspicions from morphological comparisons that the species is closely related to D. eschscholtzii and D. bambusicola, both common in Thailand. Daldinia flavogranulata, one of the new taxa, was found to be closely related to the same taxa. The other two novel species, D. phadaengensis and D. chiangdaoensis, share characters with D. korfii and D. kretzschmarioides, respectively.
\end{abstract}

Keywords Ascomycota $\cdot$ Sordariomycetes $\cdot$ Chemotaxonomy $\cdot$ Three new species

\section{Introduction}

The genus Daldinia was erected by Cesati and De Notaris (1863) in honor of the Swiss monk, Agostino Daldini.

Taxonomic novelties Daldinia chiangdaoensis Srikitikulchai,

Wongkanoun, M. Stadler \& Luangsa-ard, D. flavogranulata

Srikitikulchai, Wongkanoun, M. Stadler \& Luangsa-ard, and

D. phadaengensis Srikitikulchai, Wongkanoun, M. Stadler \& Luangsaard.

Section Editor: Hans-Josef Schroers

Electronic supplementary material The online version of this article (https://doi.org/10.1007/s11557-020-01621-4) contains supplementary material, which is available to authorized users.

Marc Stadler

marc.stadler@helmholtz-hzi.de

1 Faculty of Biotechnology, College of Agricultural Innovation, Biotechnology and Food, Rangsit University, Phahonyothin Road, Rak-hok, Pathum Thani 12000, Thailand

2 National Biobank of Thailand (NBT), National Science and Technology Development Agency (NSTDA), 111 Thailand Science Park, Phahonyothin Road, Khlong Nueng, Khlong Luang, Pathum Thani 12120, Thailand
Today, it is one of largest genera in the Hypoxylaceae (Ascomycota, Xylariales). Traditionally, Daldinia species were recognized by the internal concentric zones below the perithecial layer in their stroma and by the presence of $\mathrm{KOH}-$
3 Plant Microbe Interaction Research Team (APMT), Integrative Crop Biotechnology and Management Research Group, National Center for Genetic Engineering and Biotechnology (BIOTEC), 113 Thailand Science Park, Phahonyothin Road, Khlong Nueng, Khlong Luang, Pathum Thani 12120, Thailand

4 Helmholtz-Zentrum für Infektionsforschung GmbH, Dept. Microbial Drugs, Inhoffenstrasse 7, 38124 Braunschweig, Germany 
extractable pigments on and below their stromatal surface $(\mathrm{Ju}$ et al. 1997). The latest world monograph of the genus compiled morphological, ultra-structural, and chemotaxonomic data for more than a thousand specimens and cultures, and included a preliminary phylogeny based on ITS sequence data (Stadler et al. 2014). Daldinia species are extremely prolific secondary metabolite producers, and the metabolites of their stromata and cultures can be used as taxonomic markers, while others exert selective and prominent activities in biological systems (Helaly et al. 2018).

While the majority of Daldinia species are associated with dicots, some of them like D. bambusicola are associated with bamboo (monocot) in Thailand (Ju et al. 1997). Hsieh et al. (2005) reported that D. bambusicola is closely related to $D$. caldariorum based on TUB2 and ACTA1 sequences. In India, Daldinia graminis and D. sacchari are found on sugarcane (Dargan and Thind 1985). Narmani et al. (2018) revealed that $D$. sacchari is phylogenetically related to $D$. eschscholtzii, and even isolated two new cytochalasins, which are the characteristic stromatal metabolites of the D. eschscholtzii complex. Furthermore, several species of Daldinia produce stromata on fire-damaged woods, including $D$. vernicosa, $D$. loculata, D. caldariorum, D. gelatinoides, and D. loculatoides (Stadler et al. 2014).

Stromata of some species of Daldinia (i.e., D. placentiformis, D. korfii, and D. kretzschmarioides) appear morphologically similar to Hypoxylon as they are lacking internal concentric zones. However, the affinities of these species to Daldinia were confirmed by ITS and TUB2 sequences, and by the fact that stromata of $D$. korfii contain cytochalasins and concentricol B (Sir et al. 2016b). These compounds can be used as molecular markers for $D$. concentrica, $D$. eschscholtzii, and some members of the D. eschscholtzii group (Quang et al. 2002; Stadler et al. 2014). Morphologically, D. kretzschmarioides is very closely linked to Hypoxylon, while multiple loci analyses and metabolomics profiles indicate a closer relationship with Daldinia (Wongkanoun et al. 2019). The phylogenetic affinities of Daldinia and allied genera were also recently confirmed using a multi-locus phylogeny in two independent studies by Wendt et al. (2018) and Daranagama et al. (2018). They used many type and authentic strains of the stromatic Xylariales, which led to a rearrangement of the genera, and provided a phylogenetic backbone tree of these pyrenomycetes for the first time. Recently, some strains representing important lineages of the Hypoxylaceae have been selected for a phylogenomic study relying on high quality genomes and the first papers on comparative functional genomics (Wibberg et al. 2020) and on the occurrence of ITS polymorphisms (Stadler et al. 2020) have been published. Nevertheless, numerous species of the Hypoxylaceae remain to be recollected and cultured, and new taxa are steadily being discovered in particular from tropical countries.
In the course of taxonomic studies on stromatic Xylariales in Thailand, involving extensive field work, we have recently encountered three new species and a new record for the country. The present study is dedicated to their description and illustration, and we also provide evidence on their phylogenetic position and their chemotaxonomy.

\section{Materials and methods}

\section{Survey and sample collection}

Stromatic Xylariales were collected in selected forests, i.e., community forests, national parks, and reforestation areas (Pha Daeng Zinc Mine area) in Thailand. Macrophotographs were taken using a Canon 60D digital camera (Canon Inc. Tokyo, Japan). Fungal cultures were obtained using a multiple spore isolation method (Sir et al. 2016a). Germinated ascospores were transferred to new agar plates. Axenic cultures and vouchers were deposited in Thailand Bioresource Research Center (TBRC, BCC) and BIOTEC Bangkok Herbarium (BBH), respectively. Scanning electron microscopy (SEM) was carried out using a conventional procedure as described by Kuhnert et al. (2017).

\section{Morphological characterizations and HPLC profiling}

Morphological characters, such as stromatal size and shapes, perithecia, asci, and ascospores were examined in accordance with Stadler et al. (2014) using an Olympus ZX31 (Olympus Corporation, Tokyo, Japan) and a dissecting microscope Olympus SZ61 (Olympus). Fungal cultures were obtained on several media, i.e., oatmeal agar (Difco OA), potato dextrose agar (Difco PDA), and yeast malt glucose agar (1\% malt extract, $0.4 \%$ glucose, and $0.4 \%$ yeast extract; agar $1 \%$; YMGA). The morphological studies were carried out on $9 \mathrm{~cm}$ Petri dishes. Conidiogenous cells and conidiophore branching patterns of the anamorph were investigated as proposed by Ju and Rogers (1996). Furthermore, stromatal color, $\mathrm{KOH}$-extractable pigments, and cultures are recorded using the color chart of Rayner (1970). For chemotaxonomic studies, stromatal secondary metabolites were extracted with acetone and analyzed using high performance liquid chromatography coupled with diode array and high resolution electrospray mass spectrometric detection (HPLC/DAD-HRESIMS) in a similar manner as described by Yuyama et al. (2018) and Kretz et al. (2019). Instrumental settings and conditions were the same as described in Kuhnert et al. (2017).

\section{DNA extraction, PCR, and sequencing}

A method based on cetyltrimethyl ammonium bromide $(\mathrm{CTAB})$ was used to extract total genomic DNA from the 
mycelia according to Mackill and Bonman (1995). The internal transcribed spacer regions (ITS), and partial sequences of the large subunit of the rDNA (LSU), RNA polymerase II $(R P B 2)$, and beta tubulin (TUB2) were amplified, following the standard primers introduced by White et al. (1990; ITS1, ITS4 and ITS5), Vilgalys and Hester (1990; LR7), Bunyard et al. (1994; LROR), Liu et al.(1999: RPB2-5F and 7Cr), and O'Donnell and Cigelnik (1997; T1 and T22), according to the protocols of Otto et al. (2016) and Wendt et al. (2018). The polymerase chain reaction (PCR) products were purified and sequenced using the same primers as used for the PCR reaction. DNA sequences were checked and assembled using BioEdit v. 7.2.5 (Hall 2013). All newly generated sequences were submitted to GenBank (https://www.ncbi.nlm.nih.gov/) and listed in Table 1.

\section{Phylogenetic analyses}

All sequences were aligned in MUSCLE (Edgar 2004) and refined by direct examination. Multiple sequence alignments were analyzed with closely matched sequences and other reference taxa obtained from GenBank as shown in Table 1. Sequences were analyzed using maximum parsimony (MP), maximum likelihood (ML), and Bayesian algorithm (MB). The MP analysis was performed in PAUP*4.0b10 (Swofford 2002), and all characters were equally weighted and gaps were treated as missing data. The most parsimonious trees were obtained from heuristic searches: 100 replicates of stepwise random addition and tree-bisection-reconnection (TBR) as branch swapping algorithm. Maximum parsimony bootstrap supports (MPBS) were estimated by 1000 replicates (10 replicates of stepwise random sequence addition). Tree length, consistency index (CI), retention index (RI), relative consistency index (RC), and homoplasy index (HI) were estimated. The ML tree and bootstrap analyses (MLBS) were conducted through the CIPRES Science Gateway V. 3.3 (Miller et al. 2010) using RAxML 8.2.4 (Stamatakis 2014) with the BFGS method to optimize GTR rate parameters. Bayesian posterior probabilities (BPP) of the branches were computed using MrBayes 3.0B4 (Huelsenbeck and Ronquist 2001) with the best-fit model $(\mathrm{GTR}+\mathrm{I}+\mathrm{G})$ selected by AIC in $\mathrm{Mr}$ Modeltest 2.2 (Nylander 2004), tested with hierarchical likelihood ratios (hLRTs). Three million generations were run in four Markov chains and sampled every 100 generations with a burn-in value set at 3000 sampled trees. Sequence alignments were deposited at TreeBase (submission ID 25485; www.treebase.org). Sequences of Graphostoma platystomum CBS 270.87 and Xylaria hypoxylon CBS12260 obtained from GenBank were used as outgroups. The RAxML based phylogenetic tree is shown in Fig. 6.

\section{Results and discussion}

\section{Molecular phylogeny}

Sixty-one new sequences were generated and included into a combined ITS, LSU, RPB2, and TUB2 dataset to clarify the phylogenetic relationships of newly collected Thai specimens of Daldinia and distinguish them from other species and genera in the Hypoxylaceae (Table 1). PCR amplifications yielded approximately $840 \mathrm{bp}$, $1213 \mathrm{bp}, 829 \mathrm{bp}$, and $1583 \mathrm{bp}$ of ITS, LSU, RPB2, and TUB2 sequences. The dataset of the multi-locus DNA sequences included 67 taxa from the Hypoxylaceae based on Annulohypoxylon (5), Daldinia (35), Hypoxylon (12), Hypomontagnella (4), Jackrogersella (3), and Pyrenopolyporus (6). The combined dataset consisted of 4465 characters, of which 2600 were constant, 1434 parsimony informative, and 431 uninformative. In MP analysis, a CI of 0.357 , a RI of 0.638 , and a HI of 0.643 yielded three equally most parsimony trees. The phylogenetic tree included 5 major clades: a Daldinia clade subdivided into five branches (D I-D V) and one clade each representing Pyrenopolyporus (Py), Hypomontagnella (Hy), Annulohypoxylon, and Jackrogersella (AJ) and Hypoxylon (H) (Fig. 6). Clade D I, accommodating D. flavogranulata (BCC 89363, BCC 89365, and BCC 89376) and D. caldariorum appeared monophyletic and was supported with high bootstrap values. These data are in agreement with the morphological characters. Clade D II also group with a strong bootstrap support and comprised D. bambusicola and $D$ brachysperma. Clade D III included the D. eschscholtzii complex, where D. placentiformis and D. theissenii were grouping as a strongly supported monophyletic clade. The strongly supported clade D IV grouped with clades D II and D III as sister clades and consisted of D. korfii, D. kretzschmarioides, D. phadaengensis (BCC 89349, BCC 89350), and D. chiangdaoensis (BCC 88220, BCC 88221). In agreement with the morphological evidence, the four taxa were separated in a highly supported clade (100\% BSMP, 100\% BSML, and 1.00 BPP). Clade D V also formed a fully statistically supported, monophyletic clade (100\% BSMP, 100\% BSML, 1.00 BPP) appearing as sister clade to clades D II and D III. Within clade D $\mathbf{V}$, two moderately supported subclades were observed; the first one consisting of $D$. andina, $D$. concentrica, $D$. dennisii, D. loculatoides, D. macaronesica, and $D$. steglichii and the second one comprising $D$. petriniae, D. pyrenaica, D. subvernicosa, and $D$. vernicosa. The fully supported clade Py contained Pyrenopolyporus species as sister clade to D V. Clade Hy included representatives of the recently erected genus Hypomontagnella (Lambert et al. 2019) represented 


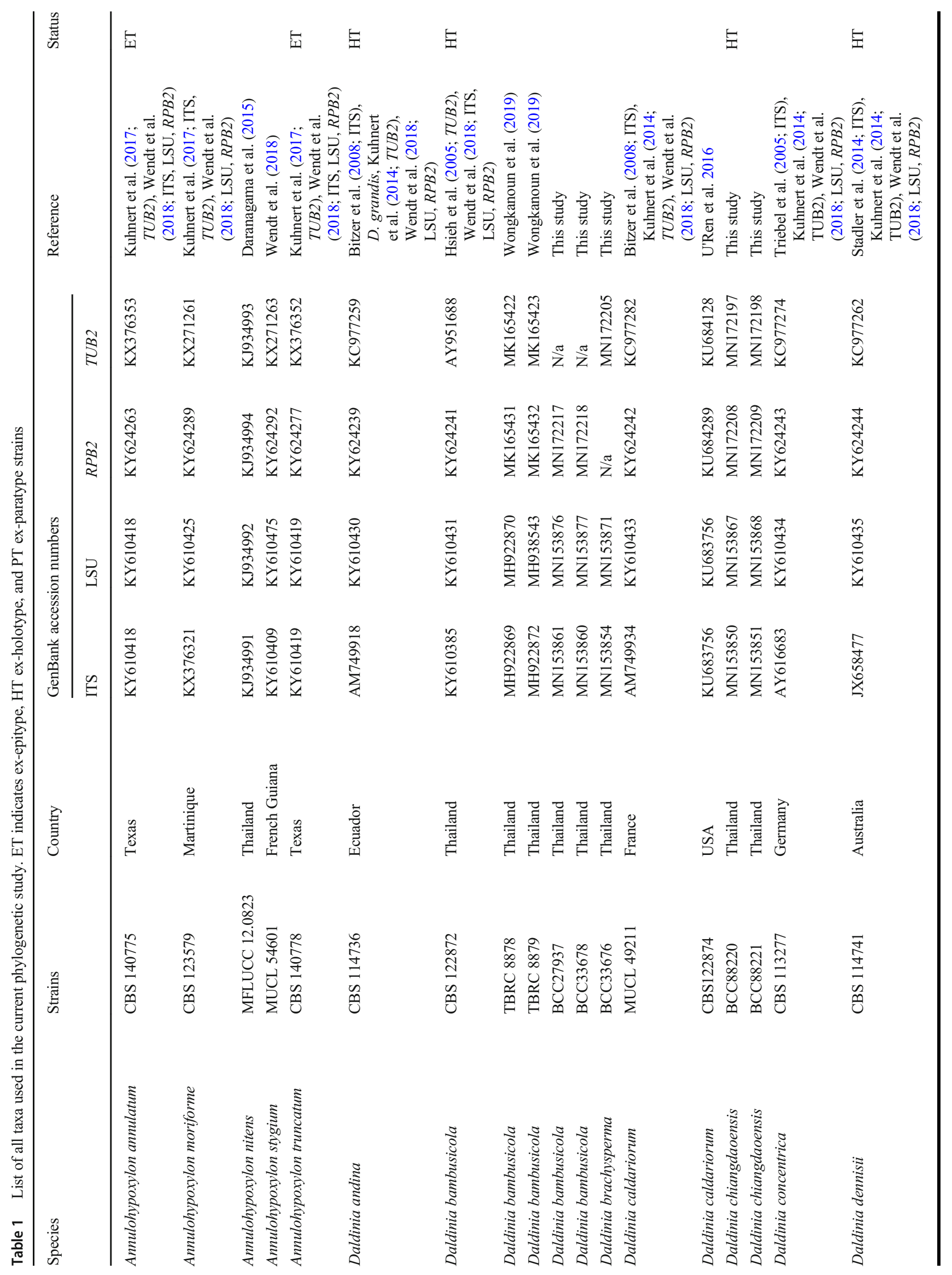




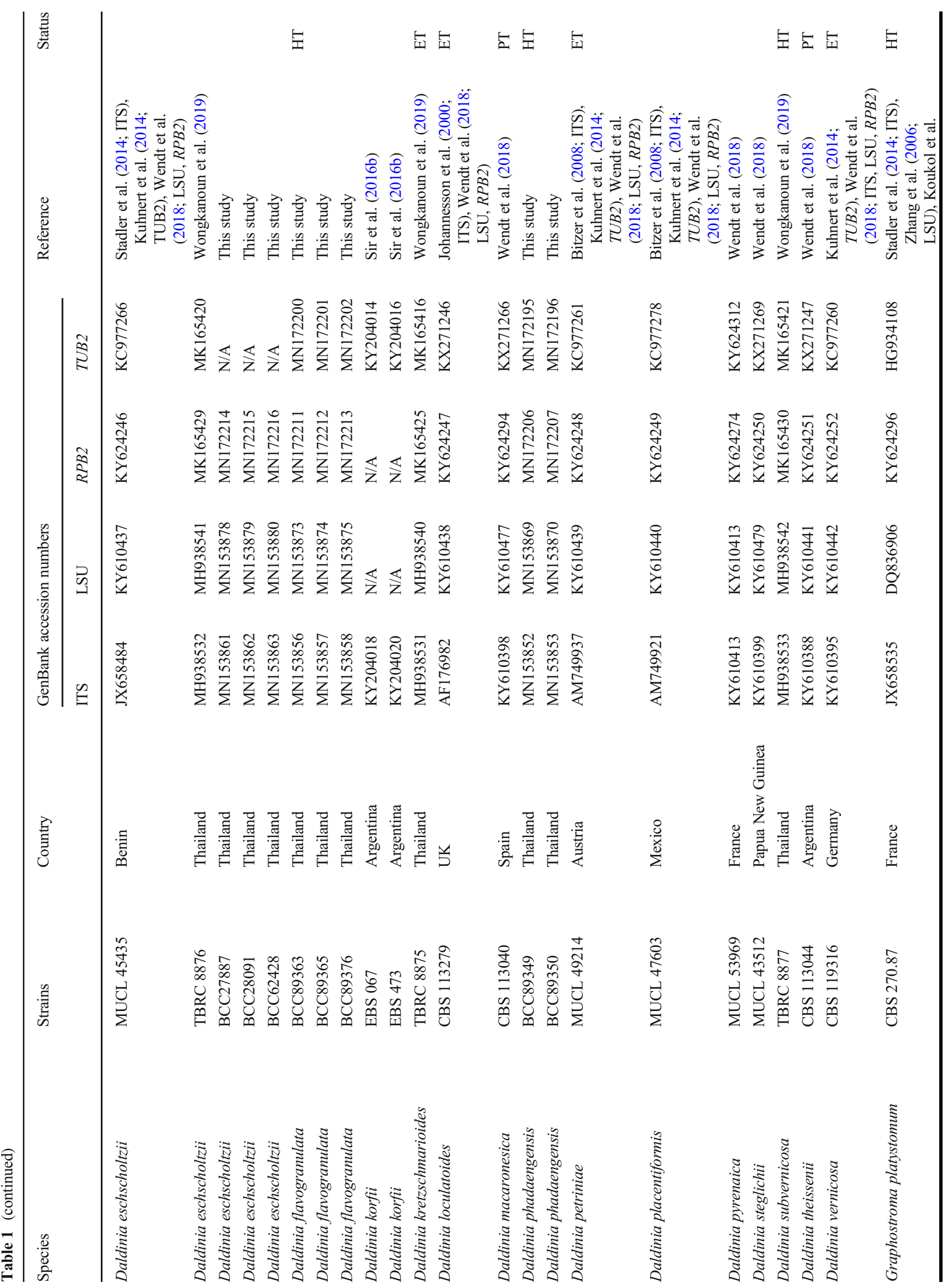




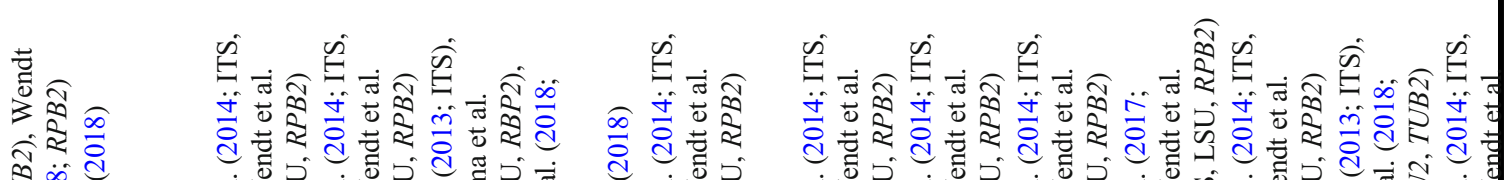

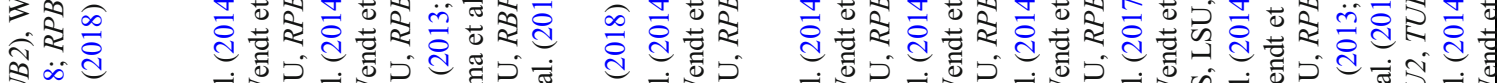

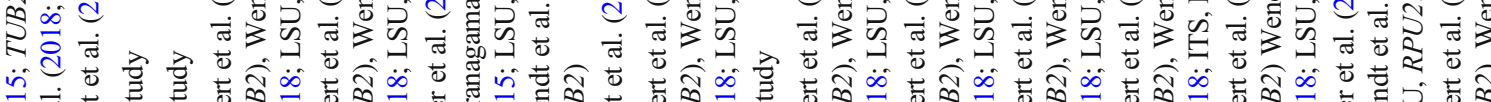

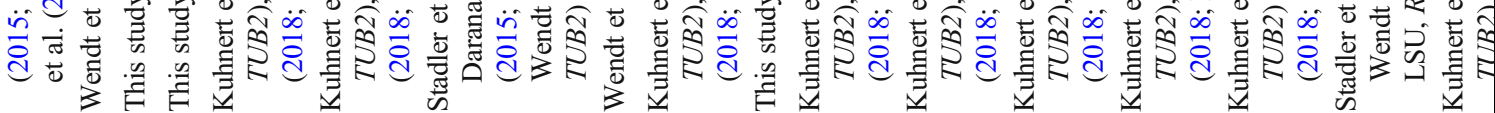

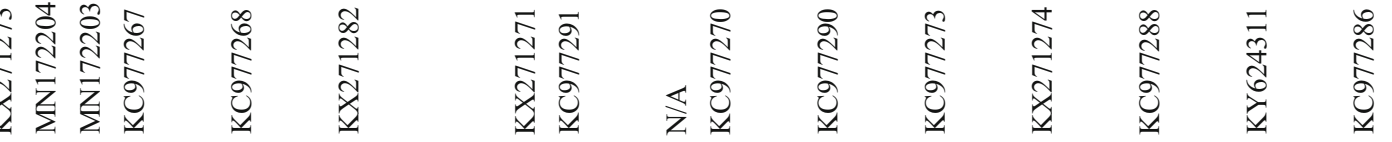

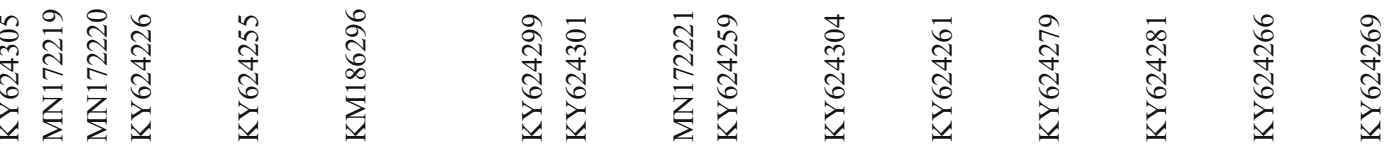

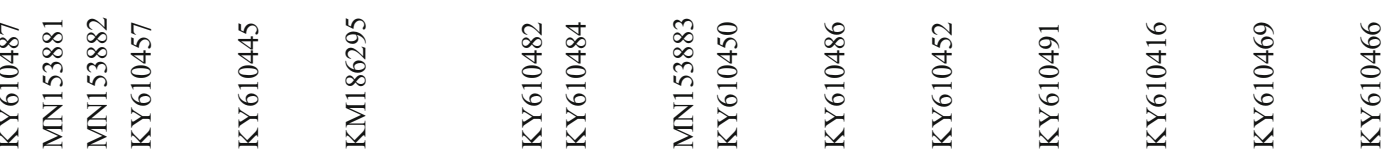

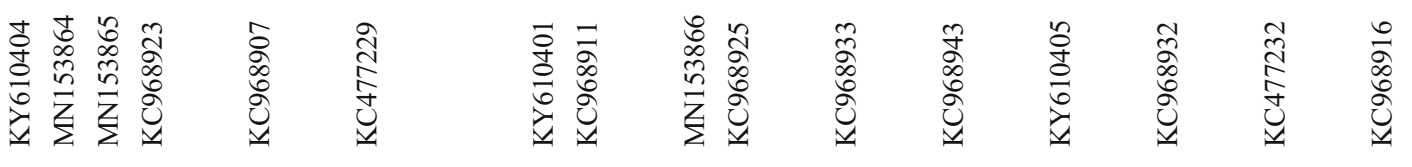

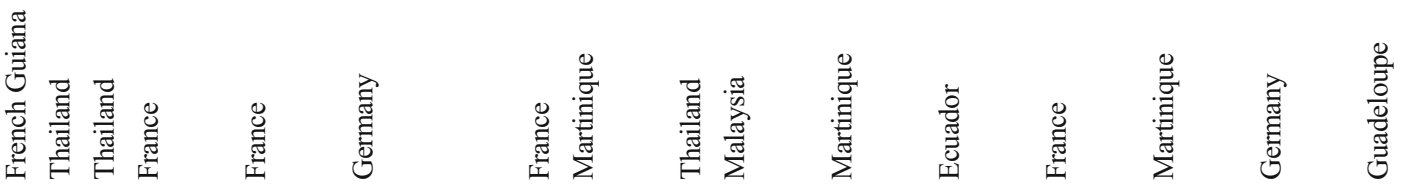




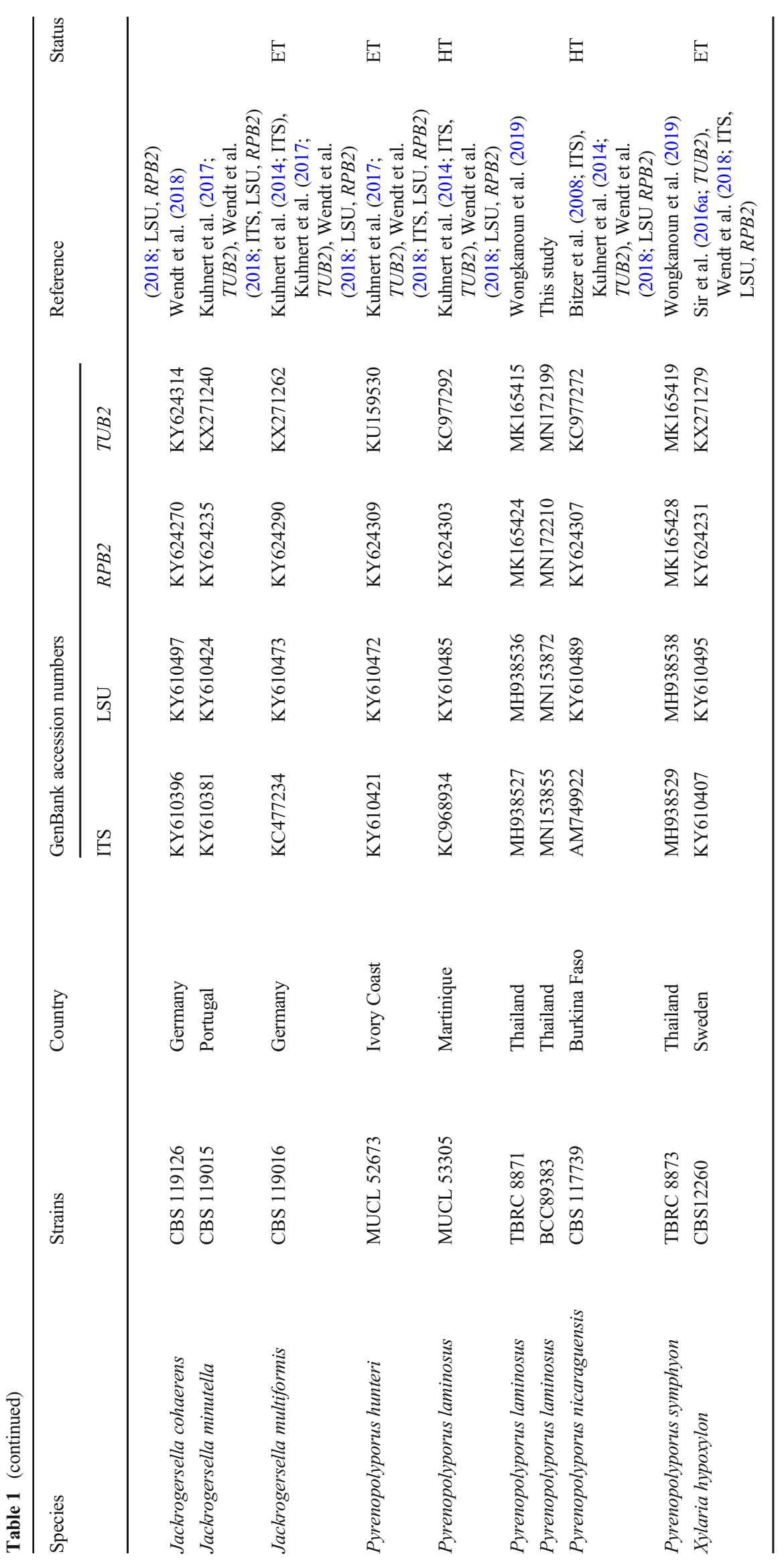


by $H$. monticulosa and $H$. submonticulosa. Clade AJ comprises species of Annulohypoxylon and Jackrogersella, while clade $\mathbf{H}$ includes species of Hypoxylon, which is in agreement with data of Wendt et al. (2018).

In summary, the phylogeny allowed for a clear separation of the taxa that are described below as new, even though the topology of the phylogenetic tree was not in accordance with the grouping of Daldinia as proposed by Stadler et al. (2014) based on ITS sequences, chemotaxonomy, and morphology. This may be due to different modes of taxon selection and the variability of ITS.

\section{Taxonomy}

Daldinia chiangdaoensis Srikitikulchai, Wongkanoun, M. Stadler \& Luangsa-ard, sp. nov. Fig. 1. MB 833760

Etymology. "chiangdaoensis" referring to the locality where the type specimen was collected.

Holotype: Thailand: Chiang Mai Province, Chiang Dao, Ban Hua Thung community forest, $19.420^{\prime}$ N, 98.971' E, hill evergreen forest, on decaying dicot wood, 13 December 2017 , P. Srikitikulchai 6 S. Wongkanoun (BBH 47512).

Ex-holotype strain: BCC 88220. DNA sequences of exholotype strain: MN153850 (ITS), MN153867 (LSU), MN172208 (RPB2), MN172197 (TUB2).
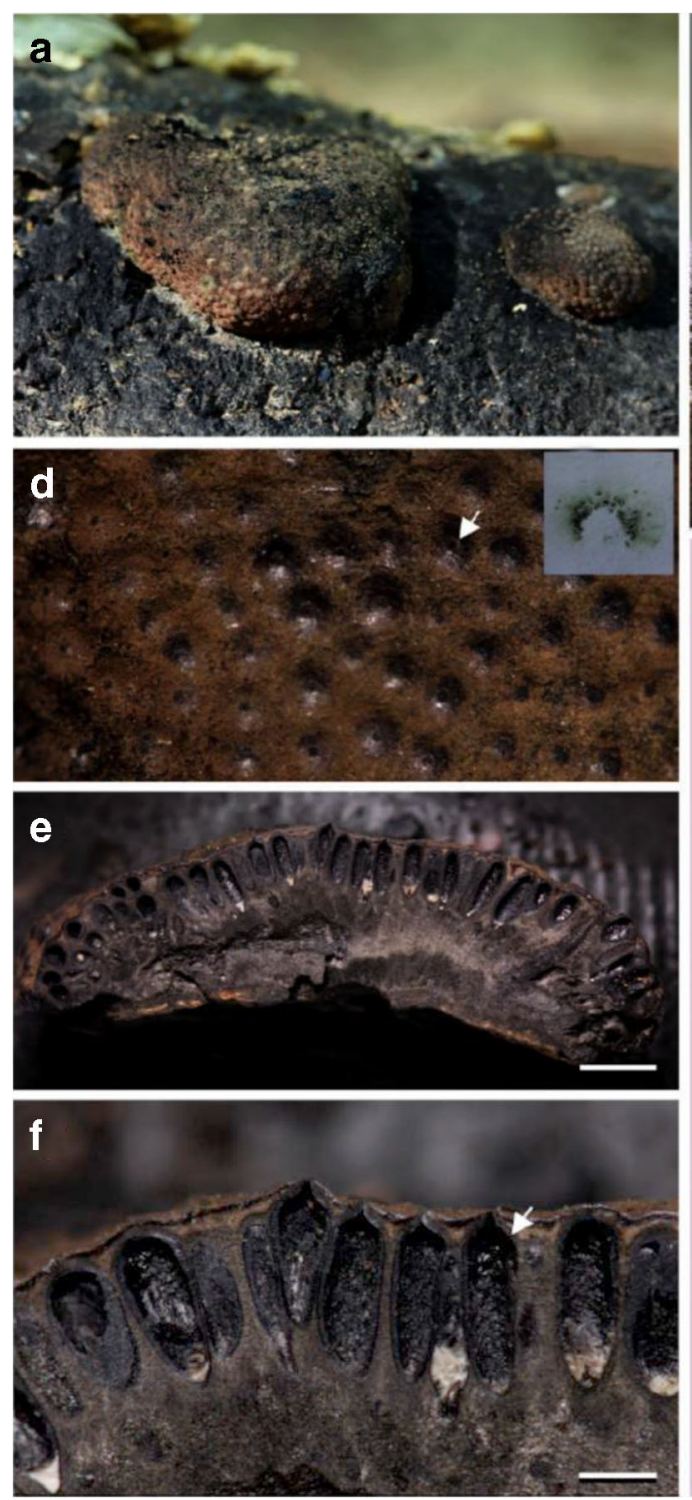

Fig. 1 Daldinia chiangdaoensis (BBH 47512). a-c Stromatal habit. d Stromatal surface and ostioles with pigments in $10 \% \mathrm{KOH}$. e Longitudinal section of stroma showing perithecia and the tissue below the perithecial layer. f Perithecia (white arrow). g Ascus. h Ascus and ascospore showing germ slit (white arrow). i Ascal apical apparatus,
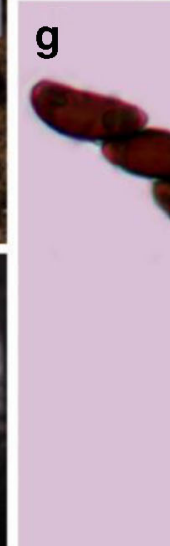
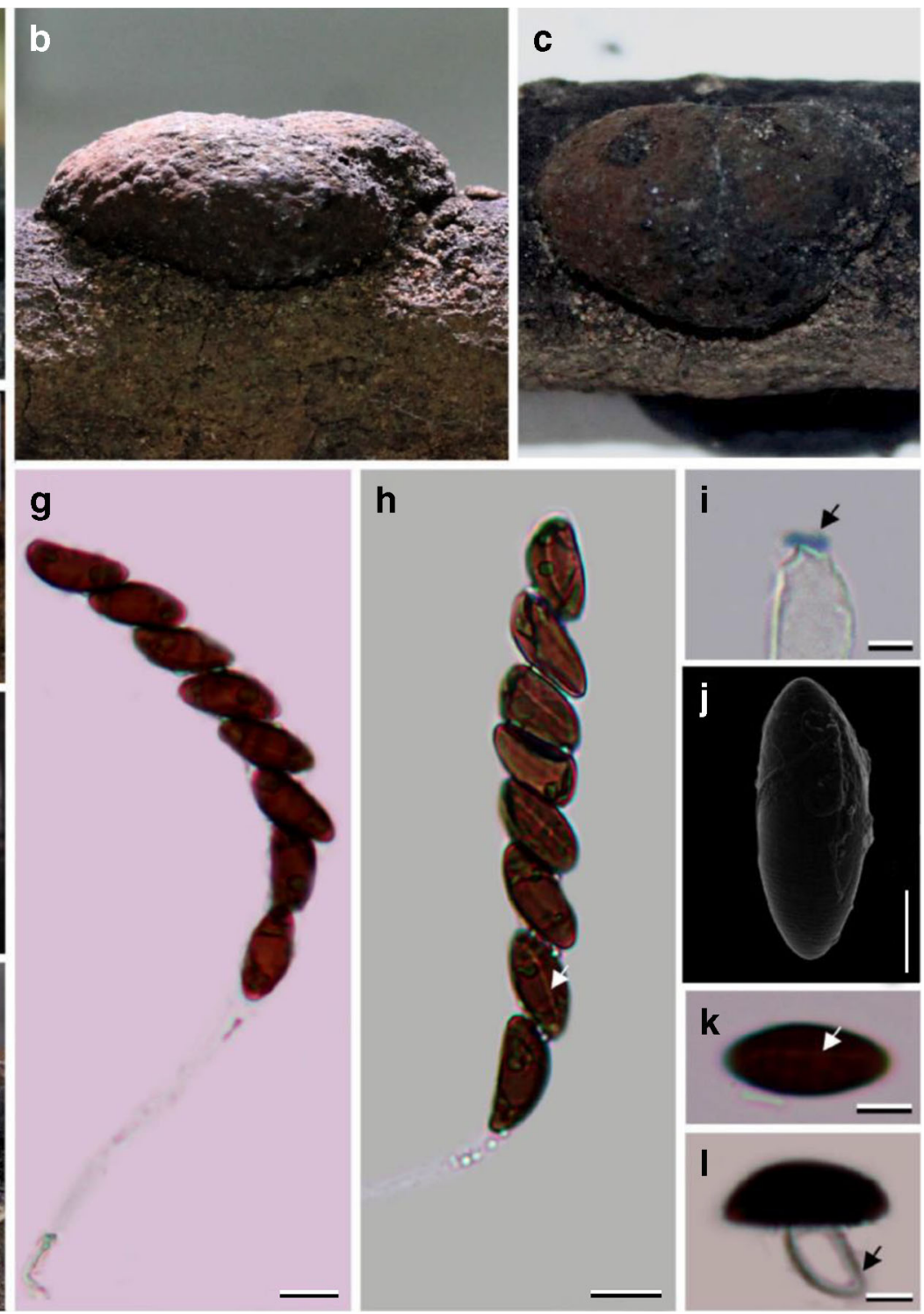

bluing in Melzer's reagent (black arrow). j Ascospore by SEM. k Ascospore showing germ slit (white arrow). I Ascospore in $\mathrm{KOH}$ showing dehiscent perispore (black arrow). Scale is indicated by bars (e $2 \mathrm{~mm}, \mathbf{f} 0.5 \mathrm{~mm}, \mathbf{g}-\mathbf{h} 10 \mu \mathrm{m}, \mathbf{i} 2 \mu \mathrm{m}, \mathbf{j}-\mathbf{l} 5 \mu \mathrm{m})$ 

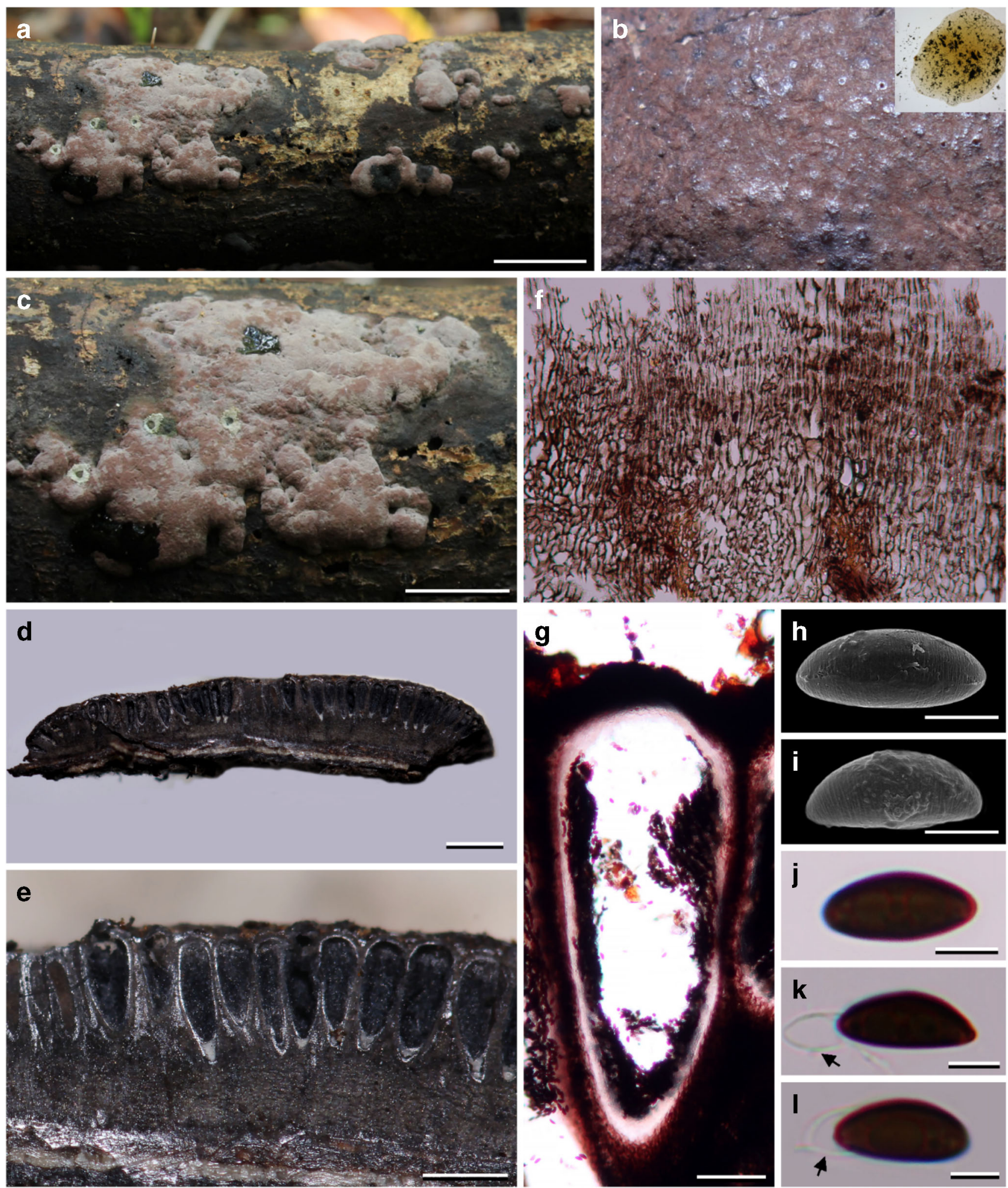

Fig. 2 Daldinia phadaengensis (BBH 47511). a, c Stromatal habit. b Stromatal surface with ostioles with pigments in $10 \% \mathrm{KOH}$. d Longitudinal section of stroma showing perithecia and the tissue below the perithecial layer. e Perithecia. f Cells of the tissue below the perithecial layer in distilled water under light microscope. $\mathbf{g}$ Perithecium in distilled water under light microscope. $\mathbf{h}-\mathbf{i}$ Ascospores by SEM. $\mathbf{j}$ Ascospore showing germ slit. k-l Ascospores in $\mathrm{KOH}$ showing dehiscent perispore (black arrow). Scale is indicated by bars (a $10 \mathrm{~mm}$, c $5 \mathrm{~mm}, \mathbf{d ~} 1 \mathrm{~mm}$, e $0.5 \mathrm{~mm}, \mathbf{g ~} 0.1 \mathrm{~mm}, \mathbf{h}-\mathbf{l} 5 \mu \mathrm{m})$ 


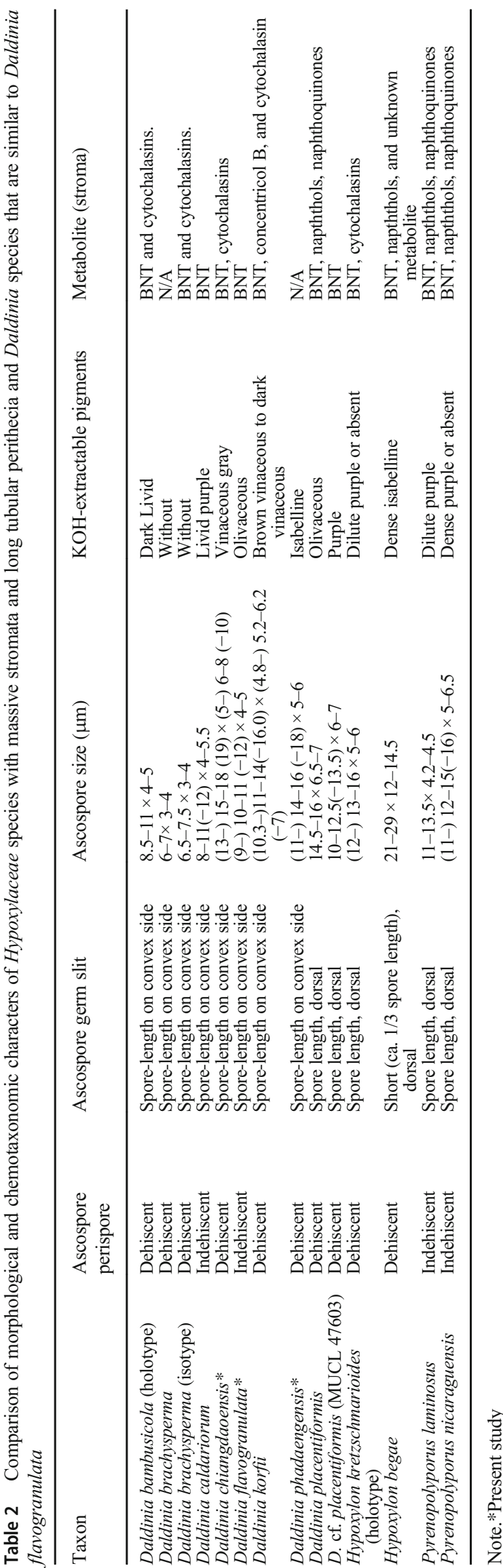

Teleomorph. Stromata superficial, hemispherical to spherical, with conspicuous perithecial outlines, (11-) 16$20 \mathrm{~mm}$ long, 9-11 $\mathrm{mm}$ broad, 4-5 $\mathrm{mm}$ thick; surface Olivaceous (48) to Dull Green (70), with $10 \% \mathrm{KOH}$ extractable pigments Vinaceous Gray (116) or Fuscous Black (104); dark brown to reddish brown granules forming a thin crust above perithecial layer; the tissue between perithecia orange brown or gray; the tissue below the perithecial layer without internal concentric zones, gray or black, 2.1-3.2 mm thick. Perithecia monostichous, obovoid to lanceolate 1.14 $1.43 \mathrm{~mm}$ high, $0.29-0.43 \mathrm{~mm}$ broad; ostioles papillate.

Asci cylindrical, spore bearing part (62-) 75-87 × 12-15 $\mu \mathrm{m}, 8$ spored; apical apparatus bluing in Melzer's reagent, discoid, (0.6-) $1 \times 1.7-2.2 \mu \mathrm{m}(\bar{x}=0.96 \times 1.93 \mu \mathrm{m}, n=10)$. Ascospores dark brown to blackish brown, unicellular, irregularly ellipsoid, with narrow rounded end (13-) 15-18 (-19) × (5-) 6-8 (-10) $\mu \mathrm{m}$ $(\bar{x}=16.45 \times 7.19 \mu \mathrm{m}, n=50)$, with straight to slightly curved germ slit covering full spore length on convex side, perispore dehiscent in $10 \% \mathrm{KOH}$, smooth.

Culture characteristics. Colonies on OA reaching the edge of the Petri dish in 3 weeks, at first whitish, becoming velvety to felty, Grayish Lavender (98); reverse Dark Purple (36) and Herbage Green (71), azonate with distinct margins (Fig. 5b1). Colonies on YMGA, reaching the edge of the Petri dish in 3 weeks, azonate, aerial mycelium at first whitish becoming velvety to felty, smoke, Rosy Vinaceous (58); reverse Olivaceous (48) (Fig. 5b2). Colonies on PDA, reaching the edge of the Petri dish $9 \mathrm{~cm}$ in 3 weeks, aerial mycelium at first whitish, becoming Rosy Vinaceous (58); reverse Olivaceous (48) (Fig. 5b3).

Anamorph on OA.Conidiophores with virgariella-like to (much more frequently) nodulisporium-like branching patterns as defined in Ju and Rogers (1996), erect, main axis hyaline to pale green and smooth to roughened. Conidiogenous cells cylindrical, hyaline, finely roughened, 11-13 $(-27) \times 3-4 \mu \mathrm{m}(\bar{x}=19.60 \times 4.3 \mu \mathrm{m}, n=5)$. Conidia hyaline to pale green, smooth, ellipsoid, 7-8 $\times 3-4 \mu \mathrm{m}(\bar{x}=$ $7.6 \times 3.6 \mu \mathrm{m}, n=10$ ).

Anamorph on YMGA. Conidiophores with the same branching pattern and dimensions of conidiogeneous cells and conidia as on OA.

Anamorph on PDA not observed even after up to 3 months.

Fig. 3 Daldinia flavogranulata (BBH 47510). a-c Stromatal habit. d Stromatal surface and ostioles with pigments in $10 \% \mathrm{KOH}$. e Longitudinal section of stroma showing the tissue below the perithecial layer producing internal concentric zones. $\mathbf{f}$ Perithecia (white arrow). $\mathbf{g}-\mathbf{h}$ Ascus with ascospores. i Ascal apical apparatus, bluing in Melzer's reagent (black arrow). $\mathbf{j}$ Ascospores showing germ slit (white arrow). $\mathbf{k}-\mathbf{m}$ Ascospore by SEM. Scale is indicated by bars $(\mathbf{e} 2 \mathrm{~mm}, \mathbf{f} 0.5 \mathrm{~mm}$, g-h $10 \mu \mathrm{m}, \mathbf{i} 5 \mu \mathrm{m}, \mathbf{j}-\mathbf{m} 2 \mu \mathrm{m}$ 

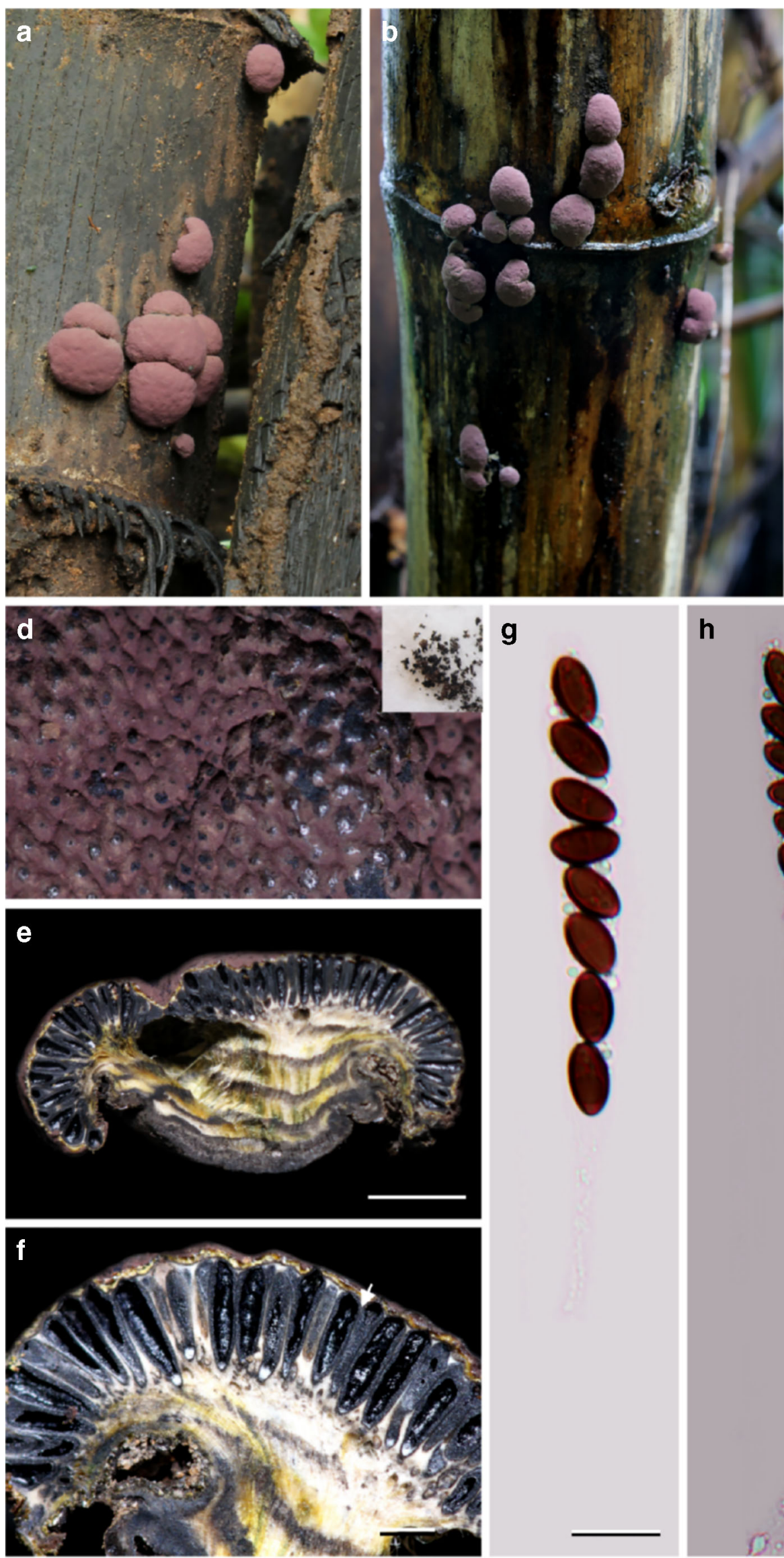

g

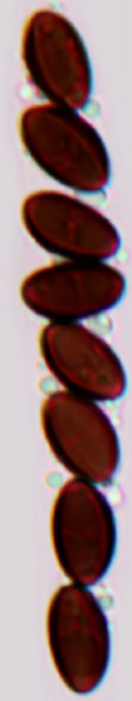

h
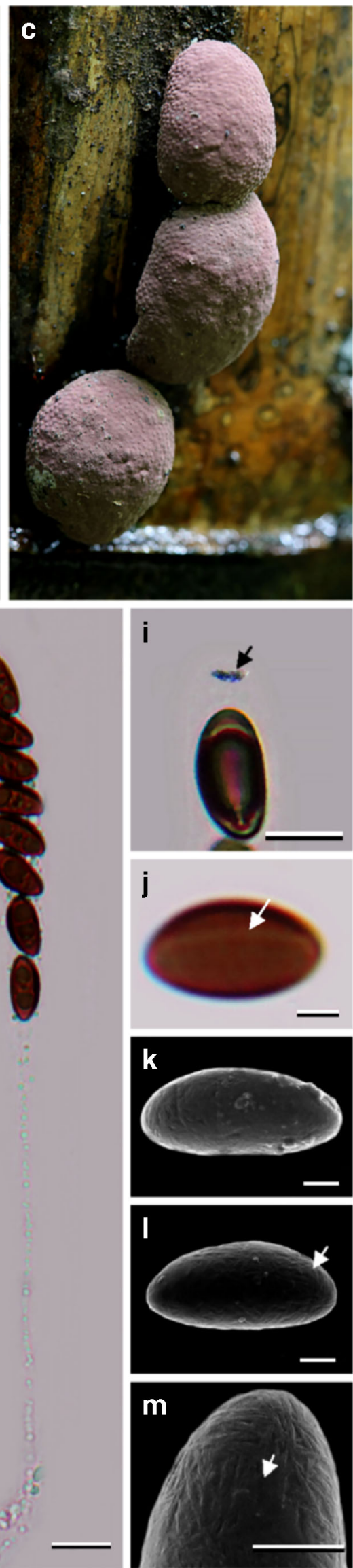

Springer 
Secondary metabolites. 1,1'-Binaphthalene-4,4',5,5'-tetrol (BNT, 1), cytochalasans (Supplementary Fig. S1).

Notes. There are three species that are most similar to D. chiangdaoensis in producing massive, azonate tissue below the perithecial layer and oboviod perithecia as the following details: D. placentiformis, D. korfii, and D. kretzschmarioides. The former species differs in its ascospores size ranges, 14.5-16 × 6.5-7 $\mu \mathrm{m}$. 1,1'-Binaphthalene4,4',5,5'-tetrol (BNT, 1) Daldinia kretzschmarioides differs in the production of a green olivaceous pigment and a brown $\mathrm{KOH}$-extractable pigment from the outer stroma. The ascospore size range of $D$. chiangdaoensis is larger than that of $D$. kretzschmarioides [(13-) 15-18 (-19) × (5-) 6-8 (-10) vs 13$15(-16) \times(4-) 5-6 \mu \mathrm{m}]$. Phylogenetic relationships revealed that DNA sequences of $D$. chiangdaoensis clustered together with $D$. kretzschmarioides supported by high bootstrap values (Fig. 6). Morphologically, D. korfii (Sir et al. 2016b) differs by its ascospores size ranges, (10.3-) 11-14 (-16) $\times(4.8-)$ $5.2-6.2(-7)$. Our molecular data also confirmed a clear separation with strong statistical support as shown in Fig. 6.

Daldinia phadaengensis Srikitikulchai, Wongkanoun, M. Stadler \& Luangsa-ard, sp. nov. Fig. 2. MB 833761

Etymology. "phadaengensis" referring to the locality where the type specimen was collected.

Holotype: Thailand: Tak Province, Pha Daeng, Pha Daeng Zinc Mine, $16.665^{\prime}$ N, 98.649' E, reforestation forest, on decaying dicot wood, 6 September 2018, P. Srikitikulchai \& S. Wongkanoun (BBH 47511).

Ex-holotype strain: BCC 89349. DNA sequences of exholotype strain: MN153852 (ITS), MN153869 (LSU), MN172206 (RPB2), MN172195 (TUB2).

Teleomorph. Stromata superficial, spreading flat over the substrate, pulvinate, with inconspicuous perithecial outlines, 15-18 (-25) mm long, 9-13 (-16) mm broad, 1.4-2 mm thick; surface Vinaceous Gray (116) to Pale Purplish Gray (117), with $10 \% \mathrm{KOH}$ producing Isabelline (65) and Cinnamon (62) extractable pigments; dark brown or blackish brown granules forming a thin crust above perithecial layer; the tissue between perithecia gray or blackish brown; the tissue below perithecial layer without internal concentric zones, gray, $0.57-0.85 \mathrm{~mm}$ thick. Perithecia monostichous, obovoid to lanceolate $0.71-0.85 \mathrm{~mm}$ high, $0.28-0.35 \mathrm{~mm}$ broad; ostioles umbilicate to slightly raised discoid.

Asci cylindrical; apical apparatus not observed. Ascospores dark brown to blackish brown, unicellular, irregularly ellipsoid, with narrow rounded ends, (11-) 14-16 (-18) $\times 5-6 \mu \mathrm{m}$ $(\bar{x} 5.45 \times 14.05 \mu \mathrm{m}, n=50)$ with straight to slightly oblique germ slit covering ca. $2 / 3$ length of the spore on convex side, perispore dehiscent in $10 \% \mathrm{KOH}$, smooth.

Culture characteristics. Colonies on $\mathrm{OA}$ reaching the edge of the Petri dish $9 \mathrm{~cm}$ in 2 weeks, zonate, at first whitish becoming Smoke Gray (106), with distinct margins; reverse
Herbage Green (18) (Fig. 5a1). Colonies on YMGA, reaching the edge of the Petri dish $9 \mathrm{~cm}$ in a week, azonate, aerial mycelium initially whitish, becoming velvety to felty, Olivaceous (48); reverse Brick (59) and Cinnamon (52) (Fig. 5a2). Colonies on PDA, reaching the edge of the Petri dish $9 \mathrm{~cm}$ in 1 week, aerial mycelium initially whitish, becoming Olivaceous (48), Dark Herbage Green (69) and yellow green (71); reverse Gray Olivaceous (107) to Smoke Gray (106) (Fig. 5a3).

Anamorph on OA. Conidiophores with virgariella-like to (much more frequently) nodulisporium-like branching patterns as defined in Ju and Rogers (1996), erect, main axis hyaline to pale green and smooth to roughened. Conidiogenous cells cylindrical, hyaline, finely roughened, $15-18(-20) \mu \mathrm{m} \times 3(\bar{x}=16.8 \times 3 \mu \mathrm{m}, n=10)$. Conidia hyaline to pale yellow, smooth, ellipsoid, 6-7 $\times 3-4 \mu \mathrm{m}(\bar{x}=$ $6.2 \times 3.04 \mu \mathrm{m}, n=25)$.

Anamorph on YMGA similar to that on OA.

Cultures on PDA not producing anamorphic structures in 3 months.

Secondary metabolites. BNT (1); daldinins A1 (2) and A4 (3) (Hashimoto 1994).

Notes. Daldinia phadaengensis is morphologically similar to D. chiangdaoensis, D. korfii, and D. kretzschmariodes in lacking internal concentric zones below the perithecial layer. The new species is distinguishable from the aforementioned species by morphology as well as by comparison of the molecular phylogenetic data. Strikingly, D. phadaengensis also differs from the other species by having yellowish orange $\mathrm{KOH}$-extractable stromatal pigments and the tissue below the perithecial layer, and has the thinnest tissue below the perithecial layer $(1.4-2 \mathrm{~mm})$ of all known Daldinia species. Table 2 provides a synopsis of the morphological characters and secondary metabolites of this group of Daldinia species and the related genus Pyrenopolyporus. Daldinia placentiformis, another morphologically similar species, which has so far not been found in Thailand, has olivaceous pigments, owing to the presence of daldinone A (Bitzer et al. 2008). Daldinin A derivatives were originally isolated from a species referred to as "D. concentrica" by Hashimoto (1994), which was revised as $D$. childiae by Stadler et al. (2014). They are chemically similar to the lenormandins and fragirubrins that are known from Hypoxylon species (Kuhnert et al. 2015; Surup et al. 2018). However, this is the first time they have been identified as a major metabolites in a species that does not belong to the $D$. childiae group as defined by Stadler et al. (2014). Several peaks corresponding to cytochalasans were also observed but could not be further elucidated without preparative isolation, which was not possible due to scarcity of material. A major unknown compound (UCP) was also detected, whose molecular formula could not yet be identified. 
Daldinia flavogranulata Srikitikulchai, Wongkanoun, M. Stadler \& Luangsa-ard, sp. nov. Fig. 3 MB 833762

Etymology. "flavogranulata" refers to the yellow granules forming a thin layer above the perithecia.

Holotype: Thailand: Tak Province, Pha Daeng, Pha Daeng Zinc Mine, $16.665^{\prime}$ N, $98.649^{\prime}$ E, reforestation forest, on bamboo trunk (Bambusoideae) in fire damaged area, 6 September 2018, P. Srikitikulchai \& S. Wongkanoun (BBH 47510).

Ex-holotype strain: BCC 89363. DNA sequences of exholotype strain: MN153856 (ITS), MN153873 (LSU), MN172211 (RPB2), MN172200 (TUB2).
Teleomorph. Stromata superficial, hemispherical, pulvinate or peltate the base broadly attached to the substrate, with conspicuous perithecial outlines, 3.6-4 cm long, 2.8$3 \mathrm{~cm}$ wide, $0.9-1 \mathrm{~cm}$ thick; surface Vinaceous Gray (116) or Purplish Gray (128), with $10 \% \mathrm{KOH}$ producing Livid Vinaceous (83) or Brown Vinaceous (84) extractable pigments; yellow granules form a thin layer above the perithecia; the tissue between perithecia blackish brown or white; the tissue below the perithecial layer Olivaceous Buff (89) and Greenish Olivaceous (90), composed of alternating zones, darker zone dark brown to a
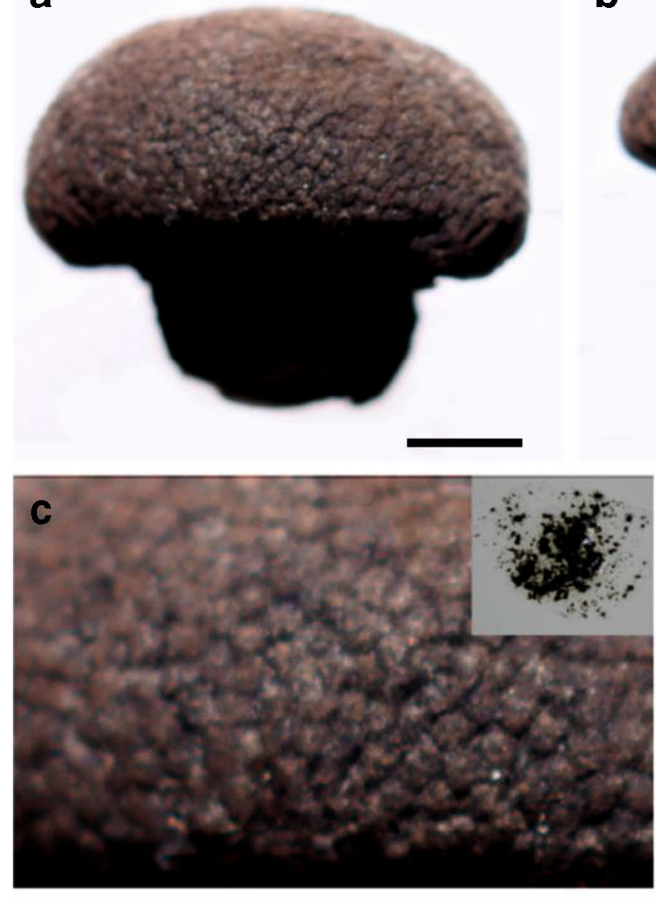

d

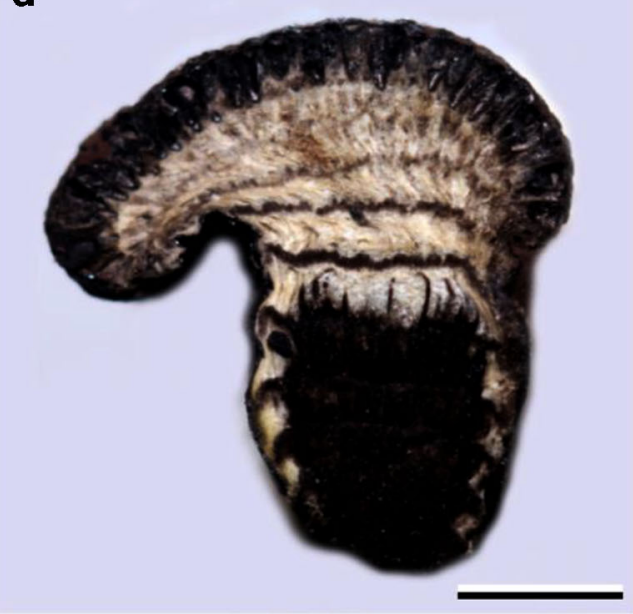

b
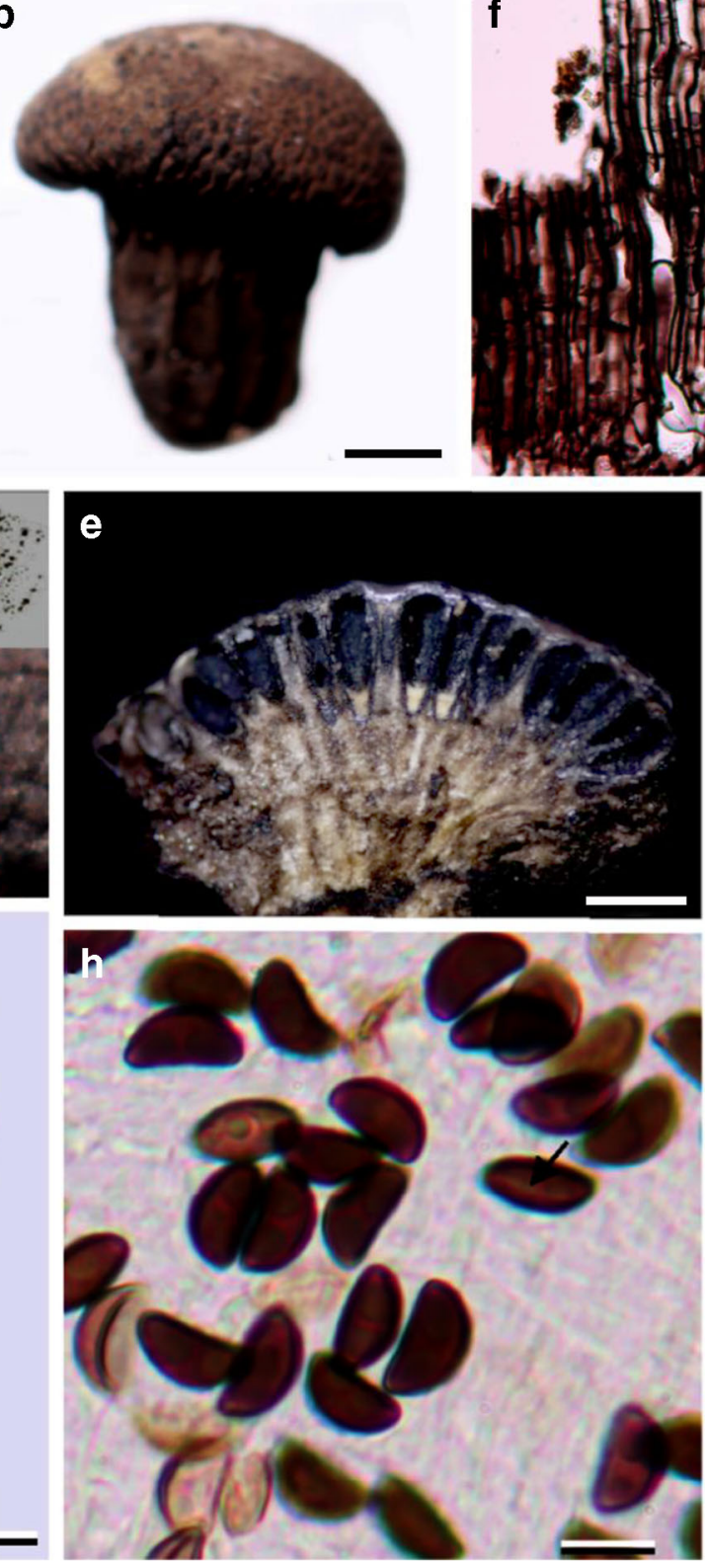

Fig. 4 Daldinia brachysperma (BBH 25493). a-b Stroma. c Stromatal surface and negative pigment test in $10 \% \mathrm{KOH}$. d Longitudinal section of stroma showing the tissue below the perithecial layer with internal concentric zones. e Perithecia. f Tissue below perithecial layer under $5 \mu \mathrm{m}, \mathbf{g}, \mathbf{i}-\mathbf{k} 2 \mu \mathrm{m})$
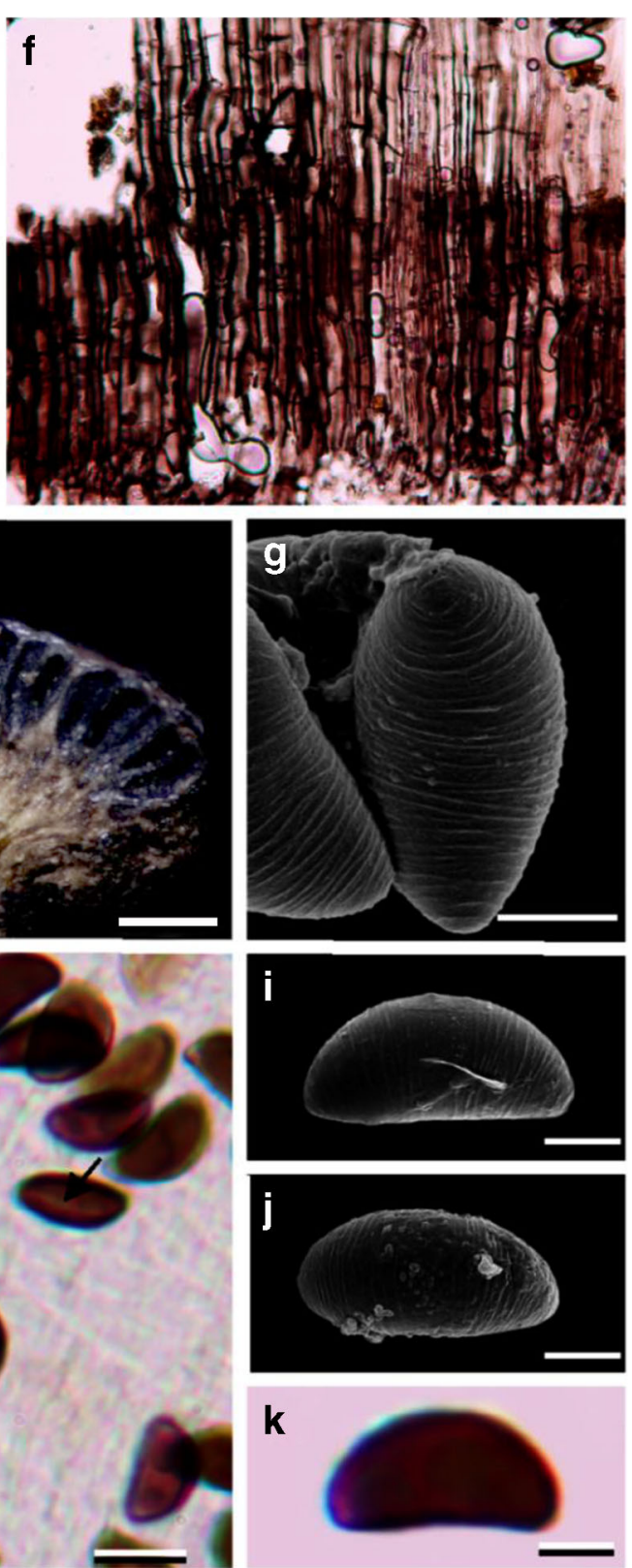

light microscope. g Ascospore by SEM. h Ascospore showing germ slit (black arrow). $\mathbf{i}-\mathbf{j}$ Ascospores by scanning electron microscopy. $\mathbf{k}$ Ascospore. Scale is indicated by bars (a, b $5 \mathrm{~mm}, \mathbf{e} 0.5 \mathrm{~mm}, \mathbf{d} 2 \mathrm{~mm}, \mathbf{h}$ 

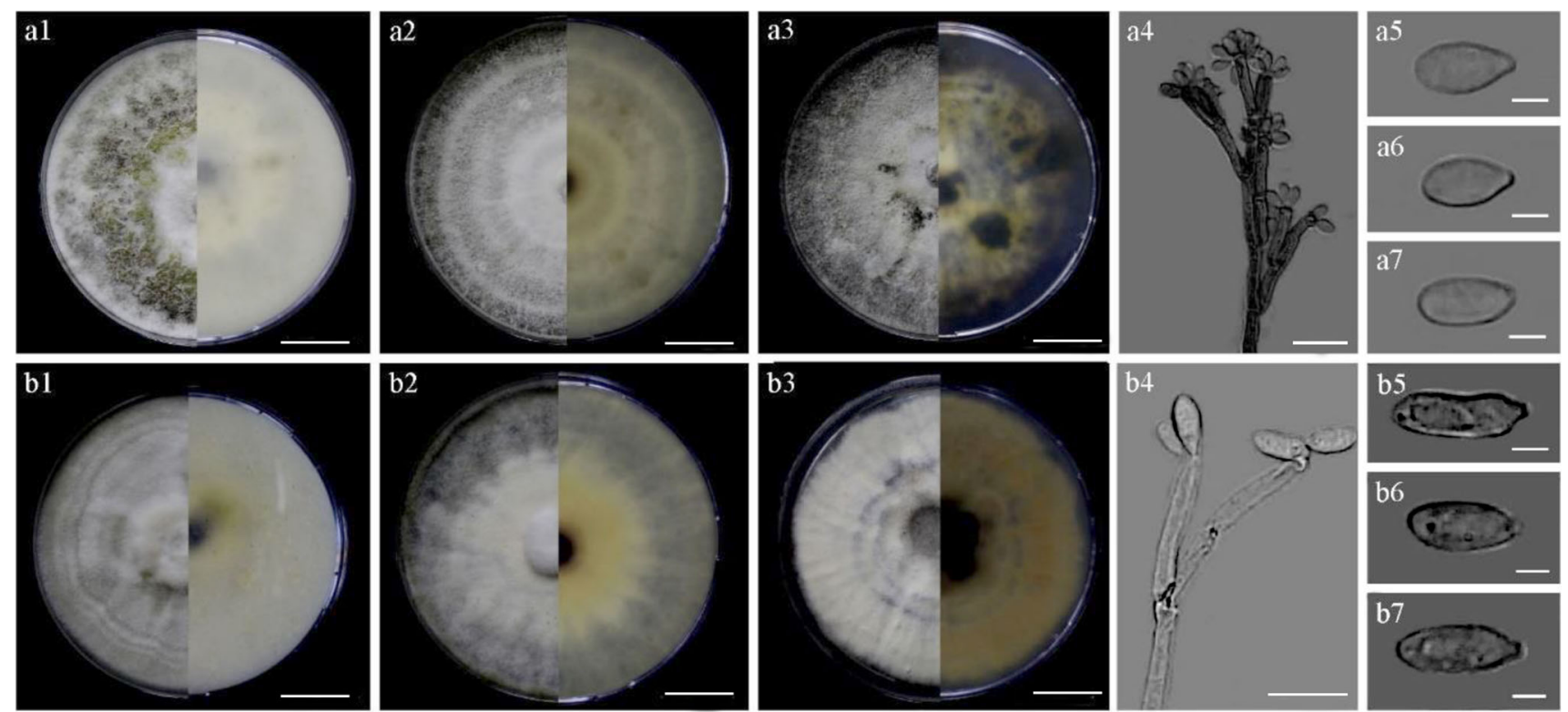

(a)
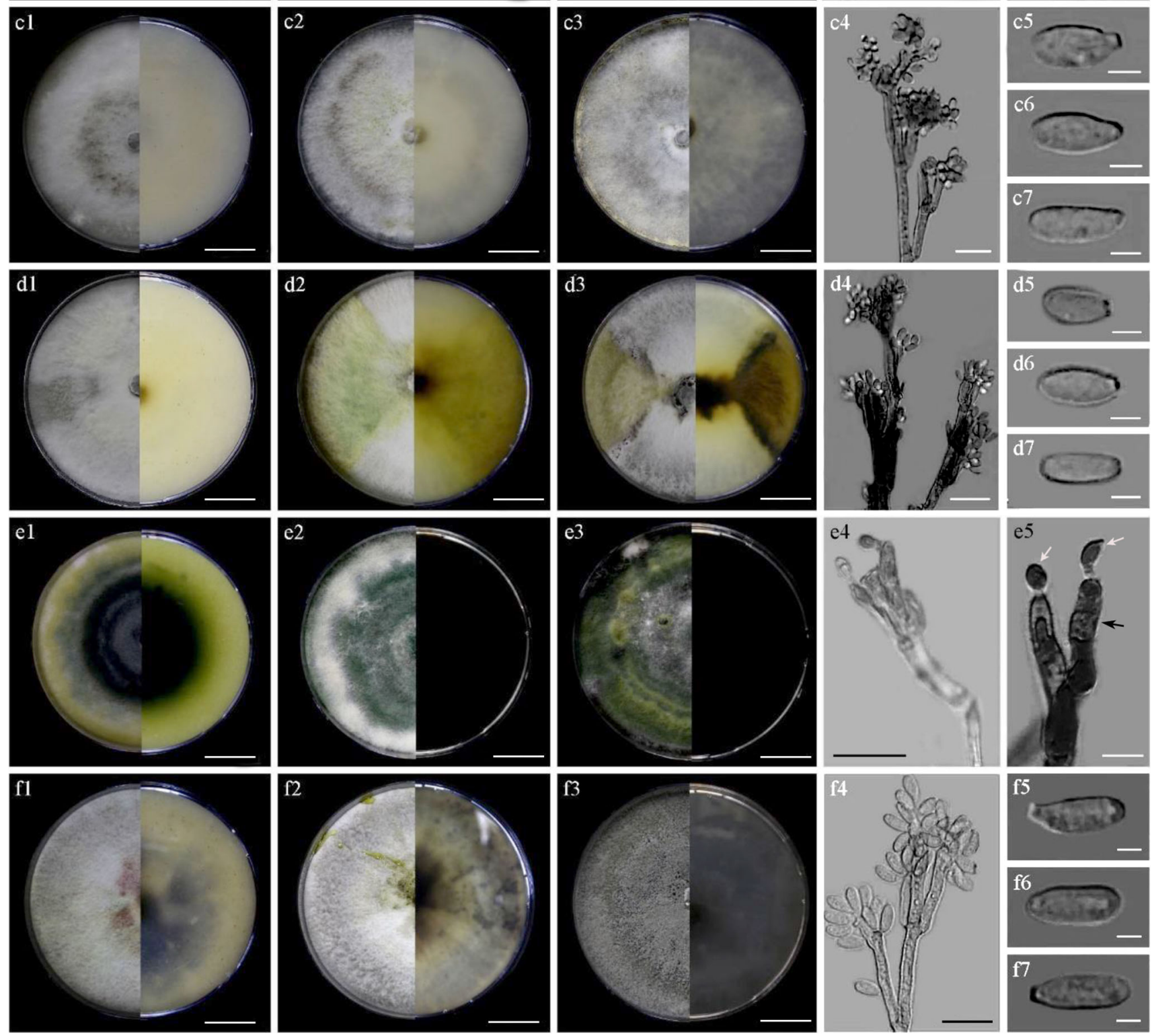
Fig. 5 Culture characteristic after 2 week incubation of Daldinia species treated in this study: D. phadaengensis (BCC 89349). a1-a7 (a1 Culture on OA, a2 Culture on YMGA, a3 Culture on PDA, a4 Conidiogenous cells, a5-a7 Conidia; D. chiangdaoensis (BCC 88220). b1-b7 (b1 Culture on OA, b2 Culture on YMGA, b3 culture on PDA, b4 Conidiogenous cells, b5-b7 Conidia); D. brachysperma (BCC 33676). c1-c7 (c1 Culture on OA, c2 Culture on YMGA, c3 Culture on PDA, c4 Conidiogenous cell, c5-c7 Conidia); D. bambusicola (TBRC 8878). d1d7 (d1 Culture on OA, d2 Culture on YMGA, d3 Culture on PDA, d4 Conidiogenous cell, d5-d7 Conidia); D. flavogranulata (BCC 89363). e1-e5 (e1 Culture on OA, e2 Culture on YMGA, e3 Culture on PDA, e4 Conidiogenous cell, e5 Conidiogenous cell (black arrow) and conidia (white arrow)); D. eschscholtzii complex (TBRC 8874). f1-f7 (f1 Culture on OA, f2 Culture on YMGA, $\mathbf{f 3}$ Culture on PDA, $\mathbf{f} 4$ Conidiogenous cell, f5-f7 Conidia). Scale is indicated by bars (a1-a3, b1-b3, c1-c3, d1-d3, e1-e3, f1-f3 2 cm; a5-a7, b5-b7, c5-c7, d5-d7, f5-f7 $2 \mu \mathrm{m} ; \mathbf{a} 4, \mathbf{b 4}, \mathbf{c 4}, \mathbf{d 4}$, f4 $10 \mu \mathrm{m}$; e4 $20 \mu \mathrm{m}$; e5 $5 \mu \mathrm{m}$ )

blackish brown $0.14-0.28 \mathrm{~mm}$ thick, lighter zones white, $0.42-0.57 \mathrm{~mm}$ thick. Perithecia monostichous, obovoid, lanceolate $0.87-1 \mathrm{~mm} \times 0.21-0.28 \mathrm{~mm}$; ostioles papillate. Asci cylindrical, 256-260 $\mu \mathrm{m}$ total length, the sporebearing part, $100-108 \times 8 \mu \mathrm{m}$; apical apparatus rectangular in outline, bluing in Melzer's reagent, 0.5-1 high, 2$2.5 \mu \mathrm{m}$ wide. Ascospores dark brown to blackish brown, unicellular, irregularly ellipsoid $(9-)$ 10-11 $(-12) \times 4-$ $5 \mu \mathrm{m}(\bar{x}=10.44 \times 4.64 \mu \mathrm{m}, n=25)$ with straight to slightly curved germ slit covering $2 / 3$ length of the spore on convex side, without dehiscing perispore in $10 \% \mathrm{KOH}$.

Culture characteristics. Colonies on OA, reaching the edge of the Petri dish in 2 weeks, zonate, at first Dark Green (21), Dark Bluish Green (24); reverse Herbage Green (17) (Fig. 5e1). Colonies on YMGA, reaching the edge of the Petri dish in 2 weeks, aerial mycelium at first whitish becoming smoke, Herbage Green (17) and Green (20); reverse Dark Green (21) and Yellow Green (18) (Fig. 5e2). Colonies on PDA, reaching the edge of the Petri dish in 3 weeks, aerial mycelium at first whitish becoming Green (50), Dark Green (21), Herbage Green (17); reverse Green (50) (Fig. 5e3).

Anamorph on OA. Conidiophores with virgariella-like to (much more frequently) nodulisporium-like branching patterns as defined in Ju and Rogers (1996), erect, main axis green olivaceous and smooth to roughened. Conidiogenous cells cylindrical, hyaline, finely roughened, 14-15 $\times 4$ $5 \mu \mathrm{m}$. Conidia hyaline, smooth, ellipsoid 4-5 $\times 2-3 \mu \mathrm{m}$.

Cultures on YMGA and PDA not producing anamorphic structures in 3 months.

Secondary metabolites. (BNT, 1) cytochalasans (Supplementary Fig. 2).

Additional materials examined. Thailand: Chiang Mai Province, Chiang Dao, Ban Hua Thung community forest, $19.420^{\prime} \mathrm{N}, 98.971^{\prime} \mathrm{E}$, hill evergreen forest; on dead monocot (Bambusae), 13 December 2017, P. Srikitikulchai \& S. Wongkanoun (BBH 42283); Tak Province, Pha Daeng, $16.667^{\prime} \mathrm{N}, 98.657^{\prime} \mathrm{E}, 520 \mathrm{~m}$ above sea level elevation, on bamboo trunk (Bambusoideae) in fire damaged area, 6
September 2018, P. Srikitikulchai \& S. Wongkanoun (BCC 89358, BCC 89365, BCC 89367, BCC 89376).

Notes. Daldinia flavogranulata closely resembles D. bambusicola, also on Bambusoideae, and has similar ascospore morphology and size range, $8.5-11 \times 4-5 \mu \mathrm{m}$. However, Daldinia flavogranulata differs in producing yellowish orange granules in a thin layer above the perithecia. Furthermore, $D$. caldariorum resembles $D$. flavogranulata in shape and size of ascospores but differs in lacking the yellowish orange granules.

Daldinia brachysperma F. San Martín, Y.M. Ju, \& J.D. Rogers, Mycotaxon 61: 255. 199 Fig. 4.

Material studied: Thailand: Chiang Mai Province, Mae Taeng, Huai Nam Dang National Park, 16.665' N, 98.649' E, hill evergreen forest, on decaying wood, 25 September 2010, P. Srikitikulchai, (BBH 25493).

Culture: BCC 33676. DNA sequences of the Thai strain: MN153854 (ITS), MN153871 (LSU), MN172205 (TUB2).

Teleomorph. Stromata superficial, stromatal surface smooth to slightly wrinkled, peltate, $2-5 \mathrm{~mm}$ high, fertile part 3-5 $\mathrm{mm}$ high, $6-8 \mathrm{~mm}$ wide, with narrow, smooth to slightly wrinkled stipe attached to substrate, with inconspicuous perithecial outlines, surface Fuscous Black (104) and Grayish Sepia (106), dull reddish brown granules immediately beneath stromatal surface, without apparent $\mathrm{KOH}$-extractable pigments; the tissue between perithecia grayish brown, pithy, woody; the tissue below the perithecial layer composed of internal concentric zones, darker zones blackish brown, $0.2 \mathrm{~mm}$ thick, lighter zones white, $0.4-0.8 \mathrm{~mm}$ thick. Perithecia monostichous, obovoid to slightly lanceolate, 0.6$0.8 \mathrm{~mm}$ high $\times 0.3 \mathrm{~mm}$ broad; ostioles slightly papillate, inconspicuous.

Asci fragmentary, without visible apical apparatus, not bluing in Melzer's reagent. Ascospores dark brown to blackish brown, unicellular, irregularly ellipsoid, with narrowly rounded to almost acute ends, 6-7 $\times 3-4(\bar{x}=$ $6.88 \times 3.48 \mu \mathrm{m}, n=25$ ), with straight to slightly oblique germ slit germ slit covering ca. 2/3 length of the spore on convex size, perispore dehiscent in $10 \% \mathrm{KOH}$, smooth under light microscope, but revealing conspicuous ornamentations by SEM; epispore smooth.

Culture characteristics. Colonies on $\mathrm{OA}$, reaching the edge of the Petri dish $9 \mathrm{~cm}$ in 1 week, azonate, at first whitish becoming floccose, Chestnut (40), Green (20), Herbage Green (17) and producing Dull Green (70) pigments, with distinct margins; reverse Pale Vinaceous (85) to Vinaceous Buff (86) (Fig. $5 \mathrm{c} 1$ ). Colonies on YMGA, reaching the edge of the Petri dish $9 \mathrm{~cm}$ in 1 week, azonate, aerial mycelium at first whitish, becoming velvety to felty, Dull Green (70), Dark Herbage Green (79) or Yellow Green (71); reverse Pale Vinaceous (85) to Vinaceous Buff (86) (Fig. 5c2). Colonies on PDA, 


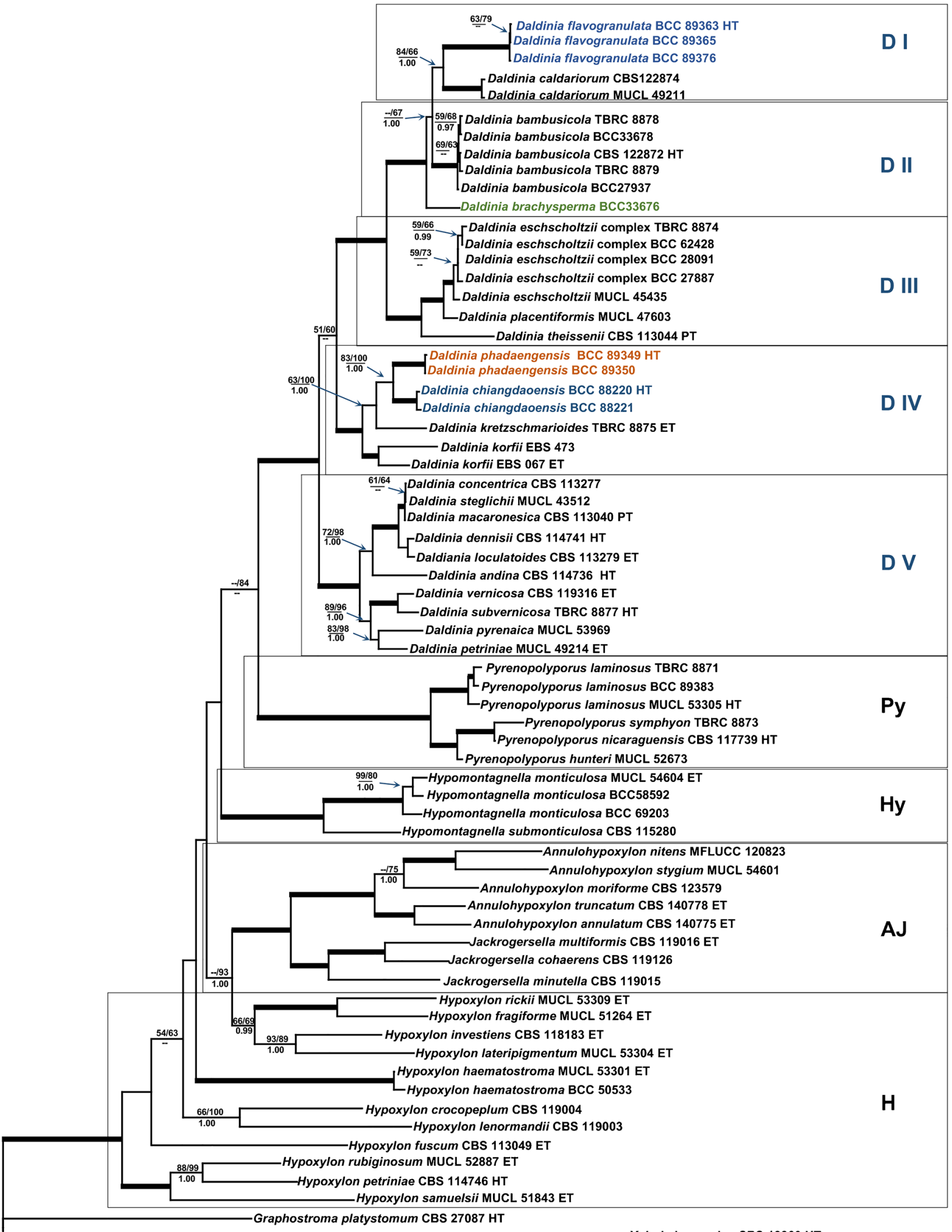

0.1

substitutions per site 
Fig. 6 Phylogeny of the Hypoxylaceae. The RAxML tree was generated based on multiple loci alignment of concatenated ribosomal (ITS and LSU) and proteinogenic (TUB2 and RPB2) sequence data. Support values were calculated via MP, ML, and Bayesian analysis and are indicated above (MPBS/MLBS) and below (BPP) the respective branches. Branches of significant support (BS $\geq 95 \%$ and $\mathrm{PP} \geq 0.98)$ are thickened

reaching the edge of the Petri dish $9 \mathrm{~cm}$ in 1 week, azonate, at first whitish, becoming floccose, Olivaceous (4); reverse Grayish Gray (110) to Olivaceous Black (108) (Fig. 5c3).

Anamorph on OA. Conidiophores with nodulisporium-like branching patterns as defined in Ju and Rogers (1996), erect, main axis hyaline to pale green and smooth to roughened. Conidiogenous cells cylindrical, hyaline, finely roughened, 10 $15(-18) \times 3-4 \mu \mathrm{m}(\bar{x}=14.00 \times 3.60 \mu \mathrm{m}, n=10)$. Conidia hyaline to pale yellow, smooth, ellipsoid, $4-5 \times 2-3 \mu \mathrm{m}(\bar{x}=4.48 \times$ $2.64 \mu \mathrm{m}, n=25)$.

Anamorph on YMGA and PDA similar to that on OA.

Secondary metabolites. BNT (1) in traces and a multitude of peaks corresponding to cytochalasans that could not further elucidated without preparative isolation, which was not possible due to scarcity of material. Additionally, two unidentifiable peaks (UCB1, UCB2) not corresponding to cytochalasans were detected.

Notes. The Thai specimen of $D$. brachysperma corresponds well with the descriptions made in Ju et al. (1997) and Stadler et al. (2014). This species is distinctive for its stromatal morphology and the characteristic short ascospores. The HPLC profile matched the data reported by Stadler et al. (2014). The phylogenetic position and the characteristics of the anamorph are reported here for the first time, and this confirmed the affinities of this species to the $D$. eschscholtzii group as postulated by Stadler et al. (2014) (Figs. 6, 7, and 8).

\section{Conclusion}

The present study focused on the taxonomy of Daldinia in Thailand, from which only four species (D. bambusicola, D. eschscholtzii, D. kretzschmarioides, D. subvernicosa) had been recorded. Here, we describe three additional novel taxa and a new

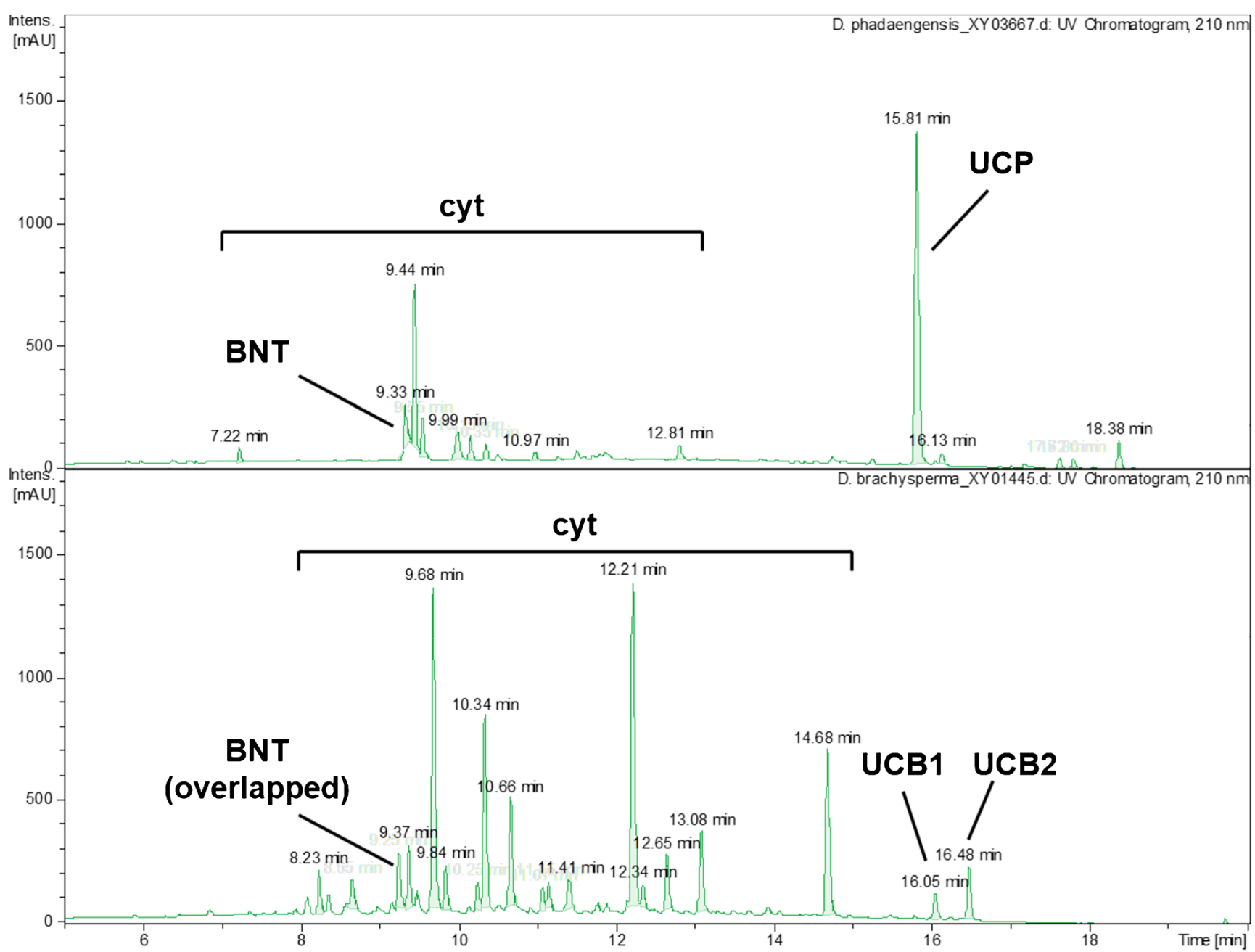

Fig. 7 HPLC-UV/vis chromatograms of stromatal extracts of Daldinia phadaengensis (top) and D. brachysperma (bottom) at $210 \mathrm{~nm}$. 1: BNT; 2: daldinin A1; 3: daldinin A4; UCP: unknown compound from $D$. phadengensis; UCB: unknown compound from $D$. brachysperma; cyt: cytochalasans 


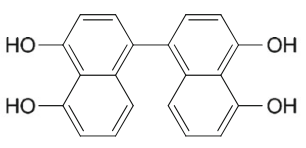

BNT (1)<smiles>[R20][C@@]1(C)C(=O)C=C2C=COC=C2C1=O</smiles>

R:

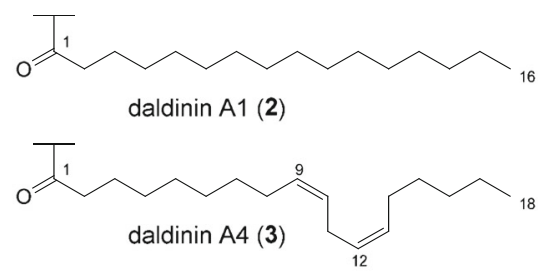

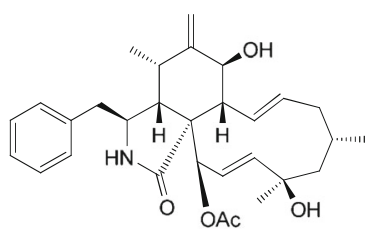

cytochalasin $\mathrm{H}$

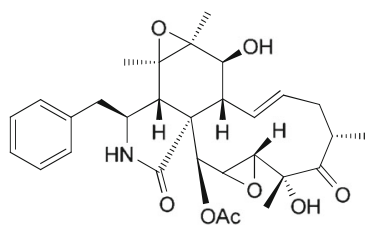

19,20-epoxycytochalasin N

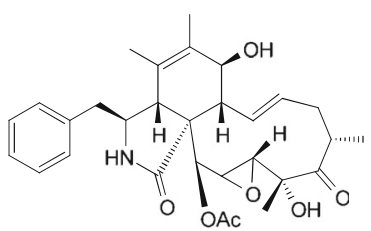

19,20-epoxycytochalasin C

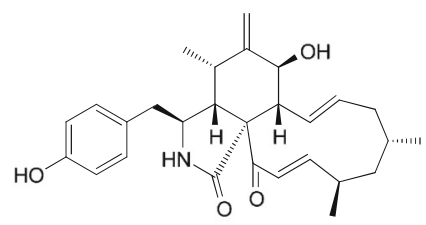

phenochalasin C
Fig. 8 Chemical structures of stromatal metabolites detected in this study as well as representative cytochalasans from Daldinia spp. as reported by Kretz et al. (2019)

record using a polyphasic approach. Several potentially new secondary metabolites have been detected in the stromata of these species by chemotaxonomic methodology, but these metabolites remain to be isolated and identified, which was not possible from the scarce stromatal material representing the type specimens. Therefore, either artificial stromata production or re-collection of the fungi in the field will be necessary in the future to accomplish this task. Daldinia as well as other genera of the stromatic Xylariales in Thailand (e.g., Pyrenopolyporus and in particular the large genus Hypoxylon) need further studies. Apart from molecular systematics and chemotaxonomy, this also concerns the generation of data based on innovative technologies such as genomics, proteomics, and metabolomic data in order to explore the full biotechnological potential of these fungi.

\section{Dichotomous key of Daldinia in Thailand}

1a Stromata associated with bamboo .2

1b Stromata not associated with bamboo 3

2a Stromata not found in fire-damaged area; ascospores dark unicellular, ellipsoid, brown to blackish brown, 8-9 (10) $\times 4-5 \mu \mathrm{m}$ D. bambusicola 2b Stromata found in fire-damaged area; ascospores dark brown to blackish brown, unicellular, ellipsoid-inequilateral (9-) 10-11 (-12) ×4-5 $\mu \mathrm{m}$

D. flavogranulata

3a Stromata with internal concentric zones below the perithecial layer..

3b Stromata without internal concentric zones below the perithecial layer

6

4a Stromata with short stout stipe; ascospores dark brown to blackish brown, unicellular, ellipsoid-inequilateral, with narrowly rounded to almost acute ends, 6-7 × 3-4 $\mu \mathrm{m}$

D. brachysperma

4b Stromata without a stipe 5

5a $\mathrm{KOH}$-extractable pigment immediately mouse gray; ascospores dark brown to blackish brown, rectangular, subglobose, often oriented transverse to the ascal axis, the basal ascospore often ellipsoid, oblong to elongate (5-) 8 $10 \times 12-15 \mu \mathrm{m}$

D. subvernicosa

5b KOH-extractable pigments mouse gray, appearing with delay (several minutes); ascospores 11-12 (-13) $\times(5-) 6-$ $7 \mu \mathrm{m}$

D. eschscholtzii

6a $\mathrm{KOH}$-extractable pigment cinnamon; scarce tissue below perithecial layer; ascospores dark brown to blackish brown, ellipsoid-inequilateral, with narrow rounded ends, (11-) 14-16 (-18) ×5-6 $\mu \mathrm{m}$

D. phadaengensis

6b $\mathrm{KOH}$-extractable pigment vinaceous; massive tissue below perithecial layer. .7

7a $\mathrm{KOH}$-extractable pigment mouse gray; ascospores ellipsoid, (4-) 5-6 × 13-15 (-16)

D. kretzschmarioides

7b KOH-extractable pigment vinaceous gray; ascospores inequilateral with narrowly rounded end (13-) 15-18 (19) $\times(5-) 6-8(-10)$

D. chiangdaoensis

Acknowledgments Sarunyou gratefully acknowledges Ton Kra Biotechnology M.Sc. scholarship from the Faculty of Biotechnology, Rangsit University. This work benefitted from the sharing of expertise within the DFG priority program "Taxon-Omics: New Approaches for Discovering and Naming Biodiversity" (SPP 1991) funded by the Deutsche Forschungsgemeinschaft, who granted a $\mathrm{PhD}$ position to K.B. The authors thank Ms. Jirawan Kumsao for sample collections in Ban Hua Thung community forest in northern Thailand. Our warmest thanks go to Christopher Lambert and Frank Surup for help with the interpretation of the HPLC profiles.

Author contributions SW did the isolation of compounds, morphological and molecular analyses as well as writing of the manuscript. MS, NB and JJL edited the manuscript, PS and KB (Rangsit University) contributed to the experimental designs. BC did the DNA extractions and PCR amplifications. KB did the chemical analysis of the stromata.

Funding Open Access funding provided by Projekt DEAL. This research was supported by the Cluster and Management Program Office (CPMO, NSTDA) grant number P-19-51796, the Technology and Innovation Management Department grant number P-18-50644 in the Pha Daeng Mine's area, Tak Province, and EU Horizon 2020 Research Innovation and Staff Exchange program (MSCA-RISE) project “GoMyTri”" Grant No. 645701. This research also benefitted from funding by the Deutsche Forschungsgemeinschaft (DFG) in the priority program "Taxon-Omics: New Approaches for Discovering and Naming Biodiversity (SPP 1991). 


\section{Compliance with ethical standards}

Conflict of interest The authors declare that they have no conflict of interest.

Open Access This article is licensed under a Creative Commons Attribution 4.0 International License, which permits use, sharing, adaptation, distribution and reproduction in any medium or format, as long as you give appropriate credit to the original author(s) and the source, provide a link to the Creative Commons licence, and indicate if changes were made. The images or other third party material in this article are included in the article's Creative Commons licence, unless indicated otherwise in a credit line to the material. If material is not included in the article's Creative Commons licence and your intended use is not permitted by statutory regulation or exceeds the permitted use, you will need to obtain permission directly from the copyright holder. To view a copy of this licence, visit http://creativecommons.org/licenses/by/4.0/.

\section{References}

Bitzer J, Læssøe T, Fournier J, Kummer V, Decock C, Tichy HV, Piepenbring M, Peršoh D, Stadler M (2008) Affinities of Phylacia and the daldinoid Xylariaceae, inferred from chemotypes of cultures and ribosomal DNA sequences. Mycol Res 112:251-270

Bunyard BA, Nicholson MS, Royse DJ (1994) A systematic assessment of Morchella using RFLP analysis of the 28S ribosomal RNA gene. Mycologia 86:762-772

Cesati V, De Notaris G (1863) Schema di classificazione degle sferiacei italici aschigeri piu' o meno appartenenti al genere Sphaeria nell'antico significato attribuitoglide Persono. Commentario della Società Crittogamologica Italiana 1(4):177-420

Daranagama DA, Camporesi E, Tian Q, Liu X, Chamyuang S, Stadler M, Hyde KD (2015) Anthostomella is polyphyletic comprising several genera in Xylariaceae. Fungal Divers 73:203-238

Daranagama DA, Hyde KD, Sir EB, Thambugala KM, Tian Q, Samarakoon MC, McKenzie EHC, Jayasiri SC, Tibpromma S, Bhat JD, Liu X, Stadler M (2018) Towards a natural classification and backbone tree for Graphostromataceae, Hypoxylaceae, Lopadostomataceae and Xylariaceae. Fungal Divers 88:1-165

Dargan JS, Thind KS (1985) Xylariaceae of India. VIII Genus Daldinia Ces \& de Not - a further segregation into two new subgenera. Kavaka 12:113-118

Edgar RC (2004) MUSCLE: multiple sequence alignment with high accuracy and high throughput. Nucleic Acids Res 32:1792-1797

Hall TA (2013) BioEdit: a user-friendly biological sequence alignment editor and analysis program for Windows 95/98/NT. Nucleic Acids Symp Ser 41:95-98

Hashimoto T (1994) Structures of daldinins A-C, three novel azaphilone derivatives from ascomycetous fungus Daldinia concentrica. Chem Pharm Bull 42:2397-2399

Helaly SE, Thongbai B, Stadler M (2018) Diversity of biologically active secondary metabolites from endophytic and saprotrophic fungi of the ascomycete order Xylariales. Nat Prod Rep 35:992-1014

Hsieh HM, Ju YM, Rogers JD (2005) Molecular phylogeny of Hypoxylon and closely related genera. Mycologia 97:844-865

Huelsenbeck JP, Ronquist F (2001) MrBayes: Bayesian inference of phylogenetic trees. Bioinformatics 17:115-755

Johannesson H, Laessøe T, Stenlid J (2000) Molecular and morphological investigation of the genus Daldinia in northern Europe. Mycol Res 104:275-280

Ju YM, Rogers JD (1996) A revision of the genus Hypoxylon. Mycologia memoir no. ${ }^{\circ} 20$. APS Press, St. Paul, 365 pp
Ju YM, Rogers JD, San Martín F (1997) A revision of the genus Daldinia. Mycotaxon 61:243-293

Koukol O, Kelnarová I, Černý K (2015) Recent observations of sooty bark disease of sycamore maple in Prague (Czech Republic) and the phylogenetic placement of Cryptostroma corticale. For Pathol 45: 21-27

Kretz R, Wendt L, Wongkanoun S, Luangsa-Ard JJ, Surup F, Helaly SE, Noumeur SR, Stadler M, Stradal TEB (2019) The effect of cytochalasans on the actin cytoskeleton of eukaryotic cells and preliminary structure-activity relationships. Biomolecules 9(2):E73.

Kuhnert E, Fournier J, Peršoh D, Luangsa-ard JJ, Stadler M (2014) New Hypoxylon species from Martinique and new evidence on the molecular phylogeny of Hypoxylon based on ITS rDNA and $\beta$-tubulin data. Fungal Divers 64:181-203

Kuhnert E, Surup F, Sir EB, Lambert C, Hyde KD, Hladki AI, Romero AI, Stadler M (2015) Lenormandins A-G, new azaphilones from Hypoxylon lenormandii and Hypoxylon jaklitschii sp. nov., recognised by chemotaxonomic data. Fungal Divers 71:165-184

Kuhnert E, Sir EB, Lambert C, Hyde KD, Hladki AI, Romero AI, Rohde M, Stadler M (2017) Phylogenetic and chemotaxonomic resolution of the genus Annulohypoxylon (Xylariaceae) including four new species. Fungal Divers 85:1-43

Lambert C, Wendt L, Hladki AI, Stadler M, Sir EB (2019) Hypomontagnella (Hypoxylaceae): a new genus segregated from Hypoxylon by a polyphasic taxonomic approach. Mycol Prog 18: 187-201.

Liu YL, Whelen S, Hall BD (1999) Phylogenetic relationships among ascomycetes: evidence from and RNA polymerase II subunit. Mol Biol Evol 16:1799-1808

Mackill DJ, Bonman JM (1995) Classifying japonica rice cultivars with RAPD markers. Crop Sci 35:889-894

Miller MA, Pfeiffer W, Schwartz T (2010) Creating the CIPRES science gateway for inference of large phylogenetic trees. Gateway computing environments workshop (GCE), IEEE, San Diego, Supercomputer Center, La Jolla, CA, USA, Nov 14, 1-8

Narmani A, Pichai S, Palani P, Arzanlou M, Surup F, Stadler M (2018) Daldinia sacchari (Hypoxylaceae) from India produces the new cytochalasins saccalasins A and B and belongs to the D. eschscholtzii species complex. Mycol Prog 18:175-185

Nylander JAA (2004) MrModeltest v. 2.0. Evolutionary biology centre. Uppsala University (program distributed by the author)

O’Donnell K, Cigelnik E (1997) Two divergent intragenomic rDNA ITS2 types within a monophyletic lineage of the fungus Fusarium are nonorthologous. Mol Phylogenet Evol 7:103-116

Otto A, Laub A, Wendt L, Porzel A, Schmidt J, Palfner G, Becerra J, Krüger D, Stadler M, Wessjohann L, Westermann B, Arnold N (2016) Chilenopeptins A and B, peptaibols from the Chilean Sepedonium aff. chalcipori KSH 883. J Nat Prod 79:929-938

Quang DN, Hashimoto T, Tanaka M, Baumgartner M, Stadler M, Asakawa Y (2002) Concentricols B, C and D, three novel squalene-type triterpenoids from the ascomycete Daldinia concentrica. Phytochemistry 61:345-353

Rayner RW (1970) A mycological colour chart. Commonwealth Mycological Institute, Kew and British Mycological Society

Sir EB, Kuhnert E, Lambert C, Hladki AI, Romero AI, Stadler M (2016a) New species and reports of Hypoxylon from Argentina recognized by a polyphasic approach. Mycol Prog 15:42

Sir EB, Lambert C, Wendt L, Hladki AI, Romero AI, Stadler M (2016b) A new species of Daldinia (Xylariaceae) from the Argentine subtropical montane forest. Mycosphere 7(5):596-614

Stadler M, Kuhnert E, Peršoh D, Fournier J (2013) The Xylariaceae as model example for a unified nomenclature following the "One Fungus-One Name" (1F1N) Concept. Mycology 4:5-21

Stadler M, Læssøe T, Fournier J, Decock C, Schmieschek B, Tichy HV, Peršoh D (2014) A polyphasic taxonomy of Daldinia (Xylariaceae). Stud Mycol 77:1-143 
Stadler M, Lambert C, Wibberg D, Kalinowski J, Cox RJ, Kolarik M, Kuhnert E (2020) Intragenomic polymorphisms in the ITS region of high quality genomes of the Hypoxylaceae (Xylariales, Ascomycota). Mycol Prog 19:235-245

Stamatakis A (2014) RAxML version 8: a tool for phylogenetic analysis and post-analysis of large phylogenies. Bioinformatics 30:13121313

Surup F, Narmani A, Wendt L, Pfütze S, Kretz R, Becker K, Menbrivès C, Giosa A, Elliott M, Petit C, Rohde M, Stadler M (2018) Identification of fungal fossils and novel azaphilone pigments in ancient carbonised specimens of Hypoxylon fragiforme from forest soils of Châtillon-sur-Seine (Burgundy). Fungal Divers 92:345356

Swofford DL (2002) PAUP*4.0b10: phylogenetic analysis using parsimony (*and other methods). Sinauer, Sunderland. https://doi.org/10. 1111/j.0014-3820.2002.tb00191.x

Triebel D, Peršoh D, Wollweber H, Stadler M (2005) Phylogenetic relationships among Daldinia, Entonaema and Hypoxylon as inferred from ITS nrDNA sequences. Nova Hedw 80:25-43

U'Ren JM, Miadlikowska J, Zimmerman NB, Lutzoni F, Stajich JE, Arnold AE (2016) Contributions of North American endophytes to the phylogeny, ecology, and taxonomy of Xylariaceae (Sordariomycetes, Ascomycota). Mol Phylogenet Evol 98:210-232

Vilgalys R, Hester M (1990) Rapid genetic identification and mapping of enzymatically amplified ribosomal DNA from several Cryptococcus species. J Bacteriol 172:4239-4246

Wendt L, Sir EB, Kuhnert E, Heitkämper S, Lambert C, Hladki AI, Romero AI, Luangsa-ard JJ, Srikitikulchai P, Peršoh D, Stadler M (2018) Resurrection and emendation of the Hypoxylaceae, recognised from a multi-gene genealogy of the Xylariales. Mycol Prog 17:115-154

White TJ, Bruns L, Lee S, Taylor J (1990) Amplification and direct sequencing of fungal ribosomal RNA genes for phylogenetics. Chapter 38. In: Innis M, Gelfand D, Sninsky J, White T (eds) PCR protocols: a guide to methods and applications. Academic Press, Orlando, pp 315-322

Wibberg D, Stadler M, Lambert C, Bunk B, Spröer C, Rückert C, Kalinowski J, Cox RJ, Kuhnert E (2020) High quality genome sequences of thirteen Hypoxylaceae (Ascomycota) strengthen the phylogenetic family backbone and enable the discovery of new taxa. Fungal Divers, in press. https://doi.org/10.1007/s13225-020-004475

Wongkanoun S, Wendt L, Stadler M, Luangsa-ard JJ, Srikitikulchai P (2019) A novel species and a new combination of Daldinia from Ban Hua Thung community forest in the northern part of Thailand. Mycol Prog 18:553-564

Yuyama KT, Wendt L, Surup F, Kretz R, Chepkirui C, Wittstein K, Boonlarppradab C, Wongkanoun S, Luangsa-ard JJ, Stadler M, Abraham WR (2018) Cytochalasans act as inhibitors of biofilm formation of Staphylococcus aureus. Biomolecules 8:129

Zhang N, Castlebury LA, Miller AN, Huhndorf SM, Schoch CL, Seifert KA, Rossman AY, Rogers JD, Kohlmeyer J, Volkmann-Kohlmeyer B, Sung GH (2006) An overview of the systematics of the Sordariomycetes based on a four-gene phylogeny. Mycologia 98: $1076-1108$

Publisher's note Springer Nature remains neutral with regard to jurisdictional claims in published maps and institutional affiliations. 